\title{
ARTICLE
}

\section{CLA-supplemented diet accelerates experimental colorectal cancer by inducing TGF- $\beta$-producing macrophages and T cells}

T. G. Moreira ${ }^{1,2,3,4}$, L. S. Horta ${ }^{2}$, A. C. Gomes-Santos ${ }^{2}$, R. P. Oliveira², N. M. G. P. Queiroz ${ }^{2}$, D. Mangani ${ }^{3}$, B Daniel ${ }^{4,7}$, A. T. Vieira ${ }^{2}$, S. Liu ${ }^{3}$, A. M. Rodrigues ${ }^{2}$, D. A. Gomes ${ }^{2}$, G. Gabriely ${ }^{3}$, E. Ferreira ${ }^{5}$, H. L. Weiner ${ }^{3}$, R. M. Rezende ${ }^{3}$, L. Nagy Nand A. M. C. Faria $^{2}$

Conjugated linoleic acid (CLA) has been shown to activate the nuclear receptor PPAR- $\gamma$ and modulate metabolic and immune functions. Despite the worldwide use of CLA dietary supplementation, strong scientific evidence for its proposed beneficial actions are missing. We found that CLA-supplemented diet reduced mucosal damage and inflammatory infiltrate in the dextran sodium sulfate (DSS)-induced colitis model. Conditional deletion of PPAR- $\gamma$ in macrophages from mice supplemented with CLA diet resulted in loss of this protective effect of CLA, suggesting a PPAR- - -dependent mechanism mediated by macrophages. However, CLA supplementation significantly worsened colorectal tumor formation induced by azoxymethane and DSS by inducing macrophage and T-cell-producing TGF- $\beta$ via PPAR- $\gamma$ activation. Accordingly, either macrophage-specific deletion of PPAR- $\gamma$ or in vivo neutralization of latency-associated peptide (LAP, a membrane-bound TGF- $\beta$ )-expressing cells abrogated the protumorigenic effect of CLA. Thus, the anti-inflammatory properties of CLA are associated with prevention of colitis but also with development of colorectal cancer.

Mucosal Immunology (2019) 12:188-199; https://doi.org/10.1038/s41385-018-0090-8

\section{INTRODUCTION}

Conjugated linoleic acid (CLA) is a mixture of positional and geometric isomers of linoleic acid (LA). ${ }^{1}$ It is naturally found in meat and dairy products derived from ruminants and it can also be endogenously produced by the enzyme delta-9-desaturase desaturation. 2,3 Humans can convert a minor proportion of vaccenic acid into CLA. ${ }^{4}$ CLA is known as a potent agonist of peroxisome proliferator-activated receptor gamma (PPAR- $\gamma)$ a nuclear receptor highly expressed in adipose tissue ${ }^{5}$ immune cells ${ }^{6}$ and gut enterocytes. ${ }^{7}$ The role of CLA in inflammatory bowel diseases (IBDs) $)^{8}$ and colorectal cancer $(C R C)^{9}$ is an emerging field of research. The discovery of PPAR- $\gamma$ as the major functional receptor mediating the aminosalicylate activity in IBD treatment ${ }^{10}$ and the impaired expression of PPAR- $\gamma$ in IBD patients ${ }^{11}$ have further enhanced the interest for the role of PPAR- $\gamma$ in the regulation of gut homeostasis with possible therapeutic implications. ${ }^{12,13}$ However, naturally occurring food components with high PPAR- $\gamma$ activation potential have been neglected and less studied than pharmacological drugs. ${ }^{12}$

Clinical studies have shown that patients with ulcerative colitis (UC) are at 30\% increased risk for developing CRC as compared to the general population. ${ }^{14}$ In addition, the incidence of both IBD ${ }^{15}$ and $\mathrm{CRC}^{16}$ is increasing worldwide. ${ }^{17}$ The precise mechanism of IBD-associated carcinogenesis is largely unknown, though it is generally assumed that it occurs as a result of an unbalanced gut mucosal inflammation/healing process caused by chronic inflammation. ${ }^{18}$ By using axozymethane (AOM)- and dextran sodium sulfate (DSS)-induced CRC in mice, a colitis-associated cancer (CAC) model, ${ }^{19}$ it is possible to observe that the tumor microenvironment suppresses the immune response as the tumor progresses, ${ }^{20}$ an effect mediated by the induction of distinct immunosuppressive cell types, including anti-inflammatory tumorassociated macrophages ${ }^{21}$ and regulatory $T$ (Treg) cells. ${ }^{22}$ The contribution of Tregs to cancer progression is uncertain. Treg accumulation in tumors has been linked to either favorable or unfavorable clinical outcomes. ${ }^{23}$ This discrepancy may be associated with different Treg cell phenotype, such as interleukin (IL)-17- and interferon- $\gamma$-producing Tregs and latency-associated peptide (LAP)-expressing Treg cells that infiltrate the tumor environment. ${ }^{24}$ Consistent with this, Scurr et al. ${ }^{25}$ described a population of Tregs that expressed LAP and CD25 and produced IL-10 and transforming growth factor- $\beta$ (TGF- $\beta$ ). Importantly, LAP+ $T$ cells were 50 -fold more suppressive and more tumorigenic than the classic FoxP3+ Treg cells in patients with CRC. ${ }^{25}$ Thus, the diversity of tumor-infiltrating Tregs poses multiple obstacles to appropriate cancer treatment.

Here we show that dietary CLA supplementation ameliorates DSS-induced colitis but contributes to the development of $A O M+D S S$-induced CRC in mice. Both anti-inflammatory and protumorigenic effects of CLA are mediated by PPAR- $\gamma$ activation in macrophages and T cells, which leads to TGF- $\beta$ production and immunoregulation.

\footnotetext{
${ }^{1}$ Departamento de Alimentos, Faculdade de Farmácia, Universidade Federal de Minas Gerais, Campus Pampulha, $31270-901$ Belo Horizonte, MG, Brazil; ${ }^{2}$ Departamento de

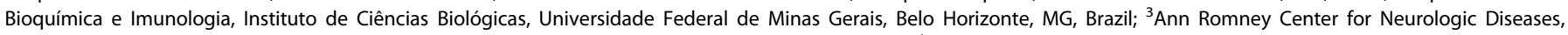

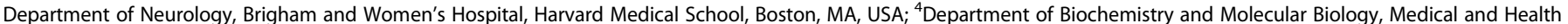

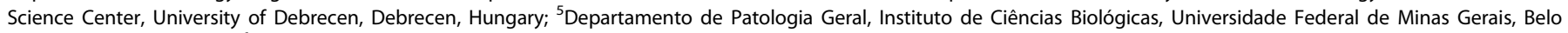
Horizonte, MG, Brazil and ${ }^{6}$ Diabetes and Obesity Research Center, Sanford Burnham Medical Research Institute, Lake Nona, Orlando, FL, USA

Correspondence: T G. Moreira (tmoreira@bwh.harvard.edu) or A M. C. Faria (anacaetanofaria@gmail.com)

${ }^{7}$ Present address: Department of Medicine, School of Medicine, Johns Hopkins All Children's Hospital, Johns Hopkins University, St. Petersburg, FL 33701, USA
}

Received: 27 April 2018 Revised: 24 August 2018 Accepted: 7 September 2018

Published online: 2 October 2018 

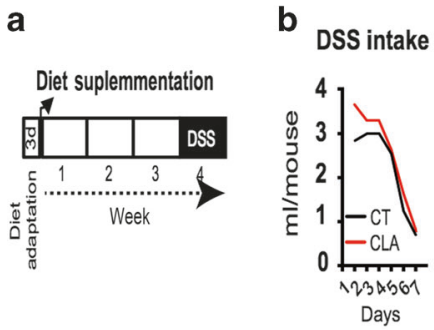

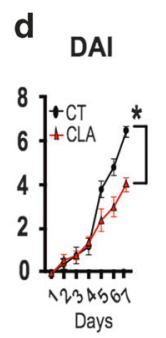

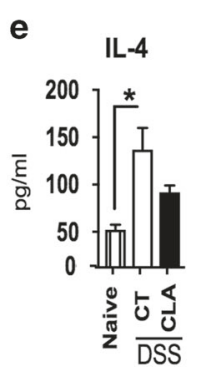

f

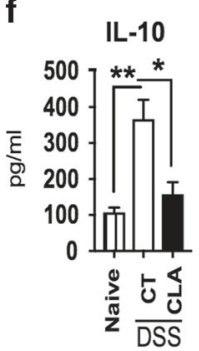

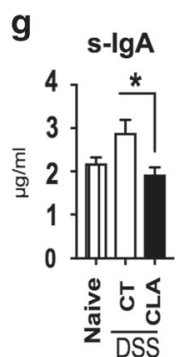

h

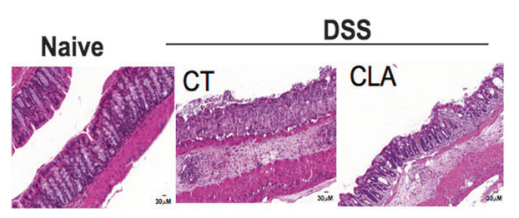

i
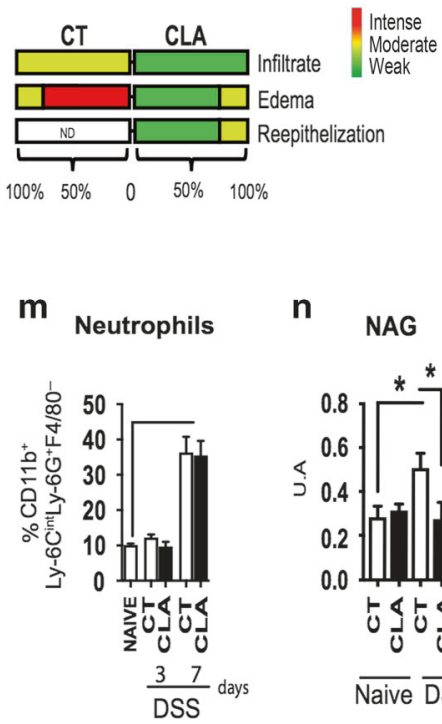

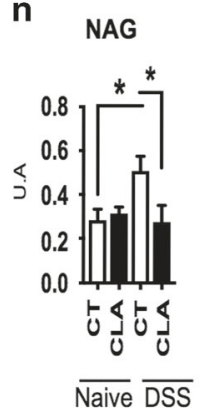

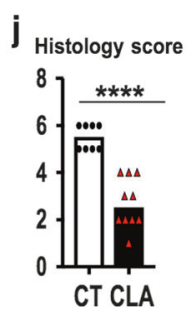

0

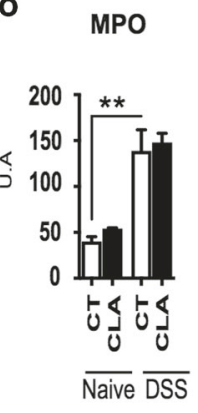

p $\mathrm{CD}^{206^{+}}$

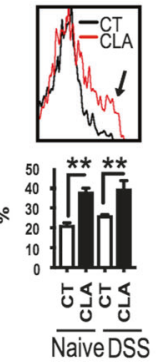

Fig. 1 CLA ameliorates DSS-induced colitis. Mice received control (CT) or 1\% CLA-supplemented diet for 4 weeks; $2 \%$ DSS was administered on the third week of diet intervention. a Experimental design. b DSS consumption within 7 days. Line represent daily average per group. c Percentage of mouse body weight within 7 days of DSS offering. d Disease activity index (DAI) represents the macroscopic score of colitis (diarrhea, fecal blood, and weight loss). Dots show mean \pm SEM. e, f Colonic cytokine production; e IL-4, $\mathbf{f}$ IL-10, $\mathbf{g}$ small intestine secretory lgA $(\mathrm{S} \lg \mathrm{A})$. $\mathbf{h} \mathrm{H} \& \mathrm{E}-\mathrm{stained}$ colonic slides $(\times 10)$. i Histological analysis considering inflammatory cell infiltrate, edema, and reepithelization. Percentage of sections is referent to each analyzed parameter in each diet group. Colors red, yellow, and green indicate the intensity of each parameter. j Histological numerical scoring system. Bars represent the median. Non-parametric Student's $t$ test with Mann-Whitney post-test was used. k Intestinal permeability measured by FITC-dextran. I, $\mathbf{m}$ Lamina propria percentage of macrophage (I) and neutrophils (m) measured by flow cytometry. $\mathbf{n}$, o $\mathrm{N}$-acetil- $\beta$-D-glucosaminidase (NAG, $\mathbf{n}$ ) and mieloperoxidase (MPO, o) activities measured in colonic tissue. $\mathbf{p}$ Immunophenotyping of colonic $\mathrm{F} 4 / 80^{+} \mathrm{CD} 206^{+}$macrophages. $N=7$ mice/group. Data are representative of at least three independent experiments. Bars represent mean \pm SEM. One-way ANOVA (e-g, k-p) and Student's $t$ test $(\mathbf{b}-\mathbf{d})$ were used. ${ }^{*} p<0.05,{ }^{* *} p<0.01$, $* * * * p<0.0001$

\section{RESULTS}

CLA supplementation ameliorates DSS-induced colitis

CLA has been shown to possess anti-inflammatory properties, ${ }^{26,27}$ however the cellular components involved in this effect remain unknown. We investigated this by supplementing mouse diet with $1 \%$ CLA for 4 weeks and inducing colitis by administering DSS in the drinking water (Fig. 1a). There was no difference in DSS intake between mice fed CLA-supplemented or control diet (CT; Fig. 1b). We showed that CLA supplementation prevented weight loss (Fig. 1c) and reduced disease activity index (DAl; Fig. 1d) as compared to CT. Increased levels of IL-4 (Fig. 1e) and IL-10 (Fig. 1f) in the colonic mucosa of DSS-treated mice were prevented by CLA supplementation. Moreover, decreased secretory immunoglobulin A (SlgA) was found in small intestine washes of mice with DSSinduced colitis and CLA supplementation maintained the basal levels of SIgA (Fig. 1g). Colonic histology showed lower inflammatory cell infiltrate and preserved mucosal architecture in mice fed CLA-supplemented diet as compared to controls (Fig. 1h). Consistent with this, less edema and more reepithelization were observed in the CLA-supplemented group (Fig. 1i, j). Gut permeability in mice with DSS-induced colitis was only detected after 5 days of DSS administration and persisted until DSS interruption (Supplementary Figure 1). Importantly, CLA supplementation prevented the increase in gut permeability (Fig. $1 \mathrm{k}$ ).

We next investigated the immune cells involved in CLA antiinflammatory effect. Macrophages and neutrophils represent important innate immune cells involved in the pathogenesis of acute DSS colitis. ${ }^{28}$ We found that macrophages appeared at the inflammatory site 3 days after DSS administration, whereas neutrophils were observed at day 7 (Fig. 1l, m). Mice fed CLAsupplemented diet showed a reduced frequency of macrophages within the lamina propria as compared to mice fed CT (Fig. 1I). Consistent with this, $N$-acetil- $\beta$-D-glucosaminidase (NAG) activity, which represents an indirect quantification of macrophage activity in tissue homogenates, was decreased in the colonic lamina propria of mice fed CLA-supplemented diet (Fig. 1n). However, no difference in neutrophil infiltration between groups was observed, as shown by flow cytometry analyses and MPO activity (Fig. 1m, o). These data suggest that monocytes/macrophages rather than neutrophils are the major players in the anti-inflammatory effect induced by CLA. Of note, macrophages $\left(C D 11 b^{+} F 4 / 80^{\text {hi }}\right)$ from the colonic lamina propria of mice fed CLA-supplemented diet expressed increased levels of CD206 (Fig. 1p), a well-known marker for anti-inflammatory macrophages ${ }^{29}$ and CX3CR1 
a

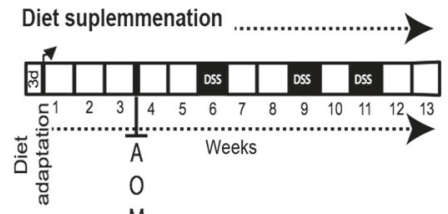

C

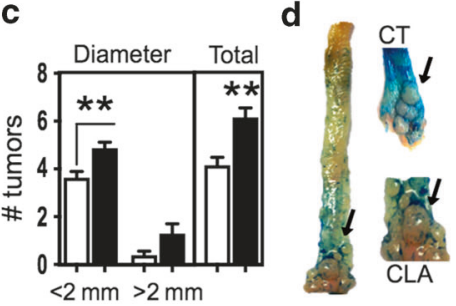

b

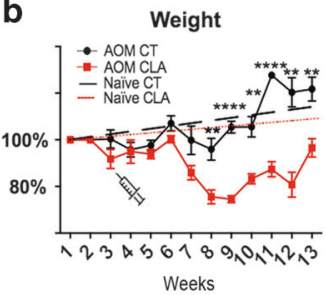

e Histology score f

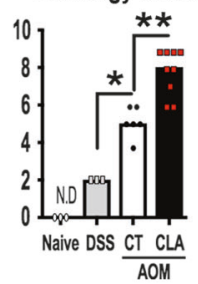

9

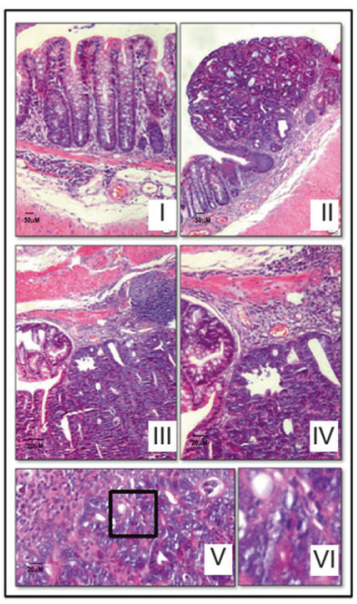

Fig. 2 CLA supplementation increases tumor formation. Mice received control (CT) or 1\% CLA-supplemented diet for 13 weeks; azoxymethane (AOM) $(10 \mathrm{mg} / \mathrm{kg}$, i.p.) and three cycles of $2 \%$ DSS. a Experimental design. b Percentage of mouse body weight during 13 experimental weeks. c Graph representation of tumor numbers classified by size. $\mathbf{d}$ Pictures representing features of colonic tumors: size and localization. e Histological numeric scoring system. Bars represent the median. Non-parametric Student's $t$ test with Mann-Whitney post-test was used $(p<0.05)$. f Percentage of colonic cells expressing CDC47 stained by immunohistochemistry. g Colonic adenocarcinoma and adenomas stained with $\mathrm{H} \& \mathrm{E}(\mathrm{I}, \mathrm{II} \times 10 ; \mathrm{III}, \mathrm{IV} \times 40 ; \mathrm{V}, \mathrm{VI} \times 60) . \mathrm{N}=9$ mice/group. Data are representative of three independent experiments. Dots and bars represent mean \pm SEM. Two-way ANOVA (b) and Student's $t$ test (c-f) were used. ${ }^{*} p<0.05,{ }^{* *} p<0.01,{ }^{* * * *} p<0.0001$

(Supplementary figure 2A), a receptor highly expressed on resident anti-inflammatory gut macrophages, ${ }^{30}$ suggesting that these cells may have regulatory functions. We did not find difference in IL-4 receptor (CD124) expression, another marker for anti-inflammatory macrophage ${ }^{29}$ between CT and CLA-treated groups (Supplementary figure 2B). Thus, CLA supplementation increases macrophages with potential anti-inflammatory properties in the colonic lamina propria of mice with DSS-induced colitis.

Of note, mucosa architecture preservation was also found in CLA-supplemented mice in a chronic model of colitis using IL-10-/- mice (Supplementary Figure 3). Thus, CLA supplementation has a potent anti-inflammatory activity in both acute and chronic experimental models of colitis.

\section{CLA supplementation increases CAC}

It is already known that a chronic inflammatory process in the gut may lead to cancer development. ${ }^{31}$ Consistent with this, CAC is the most severe complication of the chronic gut inflammation. ${ }^{18}$ Moreover, patients with UC have a higher risk for developing $\mathrm{CRC}^{14} \mathrm{CLA}$ supplementation has been shown to have anticarcinogenic properties. ${ }^{9,32}$ Because we showed that CLA had a potent anti-inflammatory effect in the DSS-induced colitis model, we initially thought that by modulating gut inflammation, CLA would prevent tumor formation in the model of CRC induced by the combination of DSS and azoxymethane (AOM). To test this hypothesis, 8-week-old $\mathrm{C} 57 \mathrm{BL} / 6$ mice received a single intraperitoneal (i.p.) injection of AOM $(10 \mathrm{mg} / \mathrm{Kg})$ after 3 weeks of diet intervention (CLA supplementation or control), followed by three alternating cycles of $2 \%$ DSS (Fig. 2a). Thirteen weeks after AOM and DSS treatment, mice were sacrificed, and tumor formation was evaluated. Mice fed CLA-supplemented diet, but not CT, lost weight (Fig. 2b). Surprisingly, CLA supplementation increased tumor formation. The average of tumor number in mice fed CT was $4.14 \pm 0.89$, whereas in mice fed CLA-supplemented diet was $6.14 \pm 1.06$ tumors (Fig. 2c, d). Moreover, multiple adenomatous formations, moderate to mild dysplasia associated with mild atypia, and discrete loss of nuclear polarization were observed in CT-fed mice (Fig. 2g-i). Intestine sections of mice supplemented with CLA diet displayed extensive sessile lesions (Fig. 2g, II) with multiple adenomatous formations, moderate dysplasia compromising muscle region of the mucosa, and isolated pseudoglandular epithelial nests (Fig. 2g, III and IV). Furthermore, in mice fed CLA-supplemented diet, we observed moderate nuclear atypia with loss of orientation and nuclear polarization with numerous mitosis (Fig. 2g, V and VI). Accordingly, CLA supplementation led to a histological score compatible with more invasive and aggressive tumors when compared to mice fed CT (Fig. 2e). Increased tumor number and histological score on CLAfed mice were also associated with high cell proliferative profile as shown by CDC47 immunohistochemistry staining of colonic cells (Fig. 2f). Thus, our data demonstrate that CLA supplementation ameliorated DSS-induced colitis but increased significantly CAC.

The anti-inflammatory effect of CLA is mediated by PPAR- $\gamma$ activation in macrophages

PPAR- $\gamma$ is a nuclear receptor highly expressed in macrophages ${ }^{6}$ and fatty acids such as CLA are natural ligands of PPAR- . $^{33}$ Increased PPAR $-\gamma$ expression detected by quantitative PCR (qPCR) was observed in bone marrow-derived macrophages (BMDM) when cultured in the presence of CLA (Supplementary figure 4). To better investigate the role of PPAR- $\gamma$ in the CLA immunomodulatory effects, we first confirmed the ability of CLA to activate PPAR- $\gamma$ by using AD293T cells transfected with luciferase under the control of PPAR- $\gamma$ gene. CLA activated PPAR- $\gamma$ in a dosedependent fashion (Fig. 3a). Of note, the PPAR- $\gamma$ agonists pioglitazone (PIO) and LA were less effective in upregulating PPAR- $\gamma$ when compared to CLA in either peritoneal or BMDM (Fig. 3b, c). Moreover, we also found that naive CD4 T cells and Foxp3-expressing Treg cells cultured in the presence of CLA induced the upregulation of Cpt1a mRNA, which has been described as a direct gene target of PPAR $-\gamma_{1}{ }^{34}$ an effect completely blocked by the PPAR- $\gamma$ antagonist GW9662 (Supplementary figure 5 ). These results suggest that in T cells CLA can activate PPAR- .

To investigate the role of PPAR $-\gamma$ in CLA immunoregulatory effects in vivo, we used Lys ${ }^{\text {Cre PPAR- }} \gamma^{\text {flox/flox }}$ mice, in which PPAR$\gamma$ is deleted specifically in macrophages. ${ }^{35}$ LysM $^{\text {Cre PPAR }} \gamma^{\text {flox/flox }}$ mice and littermate controls received either CLA-supplemented diet or CT for 4 weeks and DSS was administered in the drinking water as described above (Fig. 1a). No difference in DSS 

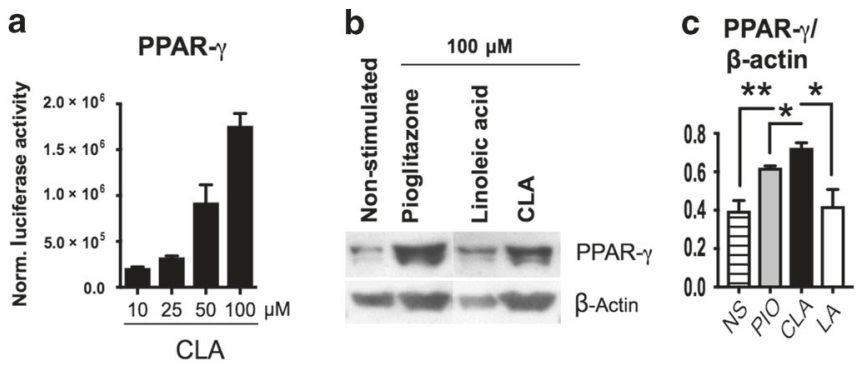

d DSS intake
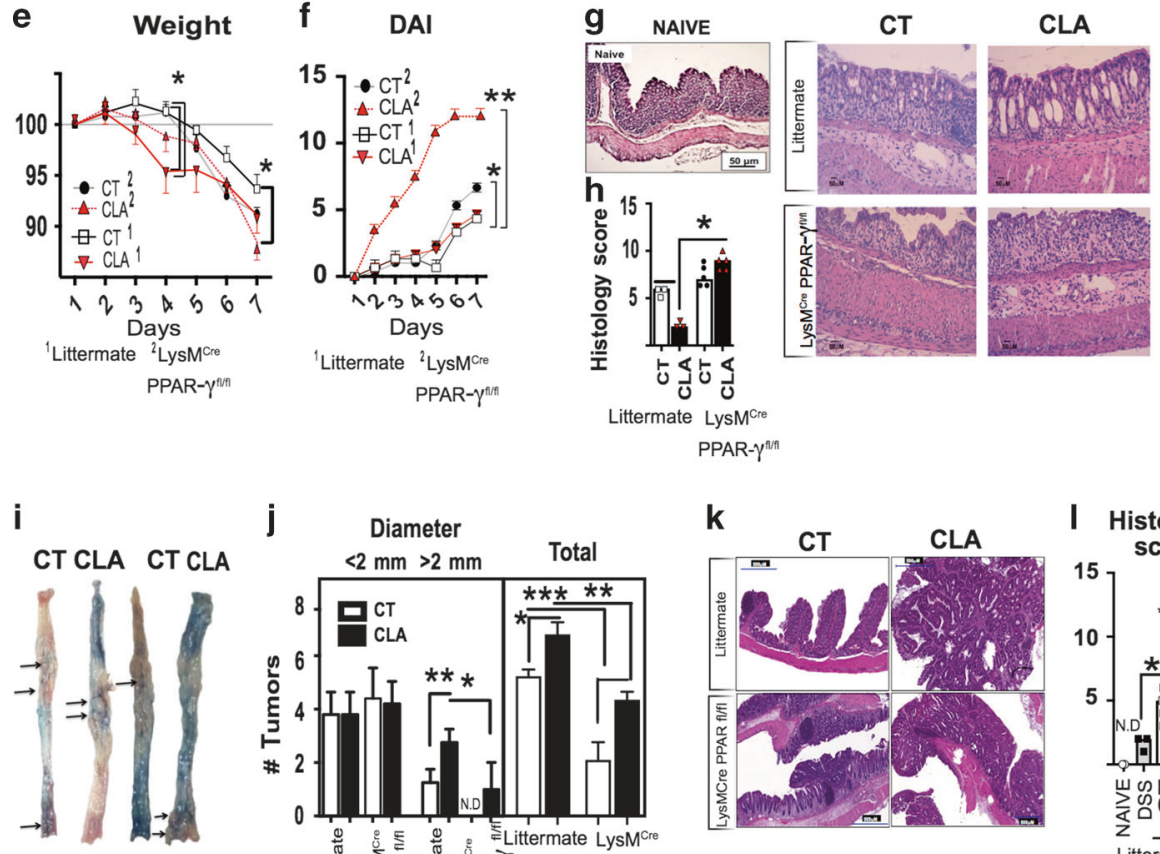

j
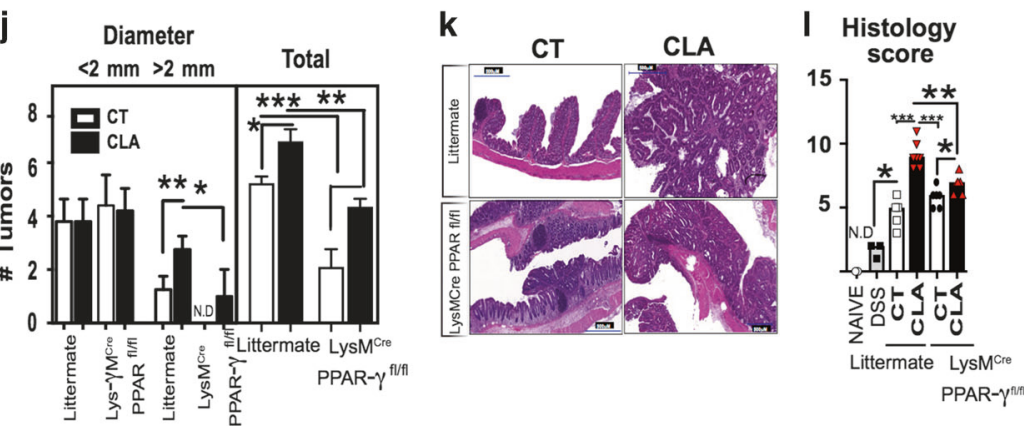

Fig. 3 CLA modulates macrophages via PPAR- $\gamma$ activation. a PPAR- $\gamma$ activity measured by luciferase assay in AD239T stimulated with 10, 25, 50, and $100 \mu \mathrm{M}$ of CLA. b PPAR- $\gamma$ expression in BMDM stimulated or not (NS) with $100 \mu \mathrm{M}$ of pioglitazone, linoleic acid (LA), or CLA for $24 \mathrm{~h}$. c Densitometry of bands found in b (PPAR- $\gamma / \beta$-actin). Data represent one assay of three independent experiments. $\mathbf{d}-\mathbf{h}$ Littermate and LysM ${ }^{\text {Cre PPAR }} \gamma^{\text {flox/flox }}$ mice received either control (CT) or $1 \%$ CLA-supplemented diet for 4 weeks; $2 \%$ DSS was administered on the third week of diet intervention; d DSS intake within 7 days. Lines represent daily average per group; e percentage of mouse body weight during DSS offering; $\mathbf{f}$ disease activity index (DAI) representing the macroscopic score of colitis (diarrhea, fecal blood, and weight loss); $\mathbf{g}$ H\&E staining of colonic tissue showing diffuse inflammatory cell infiltrate with loss of mucosal architecture $(\times 10)$; $\mathbf{h}$ histological numeric scoring system considering inflammatory cell infiltrate, edema, and reepithelization. Bars represent the median. i-I Littermate and LysM ${ }^{\text {Cre }}$ PPAR ${ }^{\text {flox/flox }}$ mice received control (CT) or $1 \%$ CLA-supplemented diet for 13 weeks; azoxymethane (AOM) (10 mg/kg, i.p.) and three cycles of DSS; i pictures representing features of colonic tumors: size and localization; $\mathbf{j}$ graph representation of tumor numbers classified by size; $\mathbf{k}$ colonic adenocarcinoma and adenomas stained with H\&E $(\times 10)$; I histological numeric scoring system evaluating the epithelial and glandular dysplasia, nuclear pleomorphism, and invasion. Bars represent the median. ND non-detected. Non-parametric Student's $t$ test with Mann-Whitney post-test $(p<0.05)$ was used for histological score $(\mathbf{h}, \mathbf{I}) . N=5$ mice/group. Data are representative of two independent experiments. Dots and bars represent mean \pm SEM. One-way ANOVA $(\mathbf{c}, \mathbf{j})$ and two-way ANOVA $(\mathbf{d}-\mathbf{f})$ were used. ${ }^{*} p<0.05,{ }^{* *} p<0.01,{ }^{* * *} p<$ 0.001

consumption between CT and CLA-treated mice was observed (Fig. 3d). Littermate controls fed CLA-supplemented diet lost less weight and had reduced DAI after DSS administation as compared

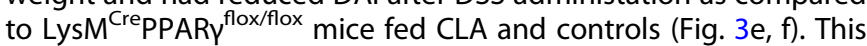
was consistent with the decreased inflammatory infiltrate and preserved gut mucosal architeture observed in CLA-fed littermate mice but not LysM ${ }^{\text {Cre PPAR }}{ }^{\text {flox/flox }}$ mice fed same diet. (Fig. $3 g$, h). Thus, the anti-inflammatory effect induced by CLA supplementation was completely abolished in LysM ${ }^{\text {CrepPAR }} \gamma^{\text {flox/flox }}$ mice suggesting that PPAR- $\gamma$ expression in macrophages is crucial for the immunoregulatory effects of CLA.

We next investigated whether PPAR- $\gamma$ activation in macrophages was also responsible for the CLA protumorigenic activity.
For this, we induced CAC on LysM ${ }^{\text {Cre PPAR }} \gamma^{\text {flox/flox }}$ and fed them with either CLA-supplemented or CT. We found that deletion of PPAR $-\gamma$ in macrophages resulted in a significant reduction of tumor numbers regardless of the diet used, as compared to littermate controls (Fig. 3i, j). As expected, dysplastic and neoplastic papillary formations with maligner features (atypical glands, two-tree layers of cells, aberrant cells, and loss of polarization) were associated with CLA consumption by littermate controls, whereas in the control group only moderate neoplastic lesions with adenomatous formations were observed. Although the number of tumors were reduced in Lys ${ }^{\text {Cre PPAR }} \gamma^{\text {flox/flox }}$ mice fed CT as compared to littermate controls, the histological analysis showed moderate multifocal inflammation lesions and mild 


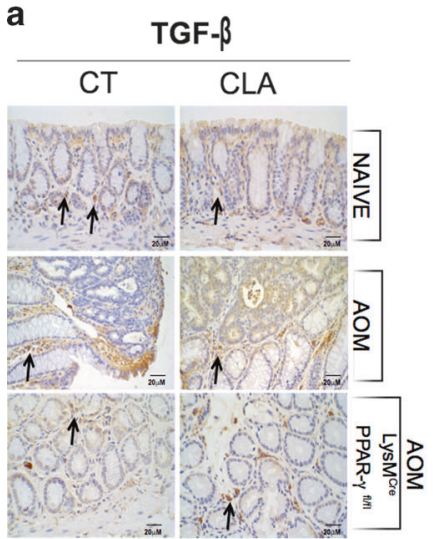

b

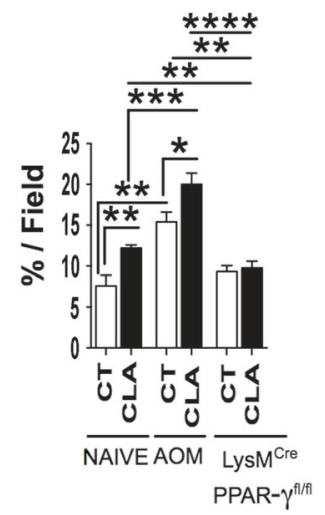

F4/80 TGF- $\beta$ Nuclei Merged

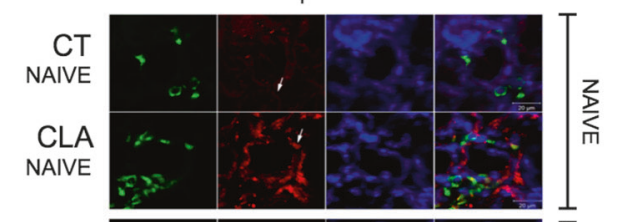

CT
AOM
CLA
AOM
CT

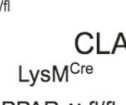

PPAR $-\gamma$ fl/fl
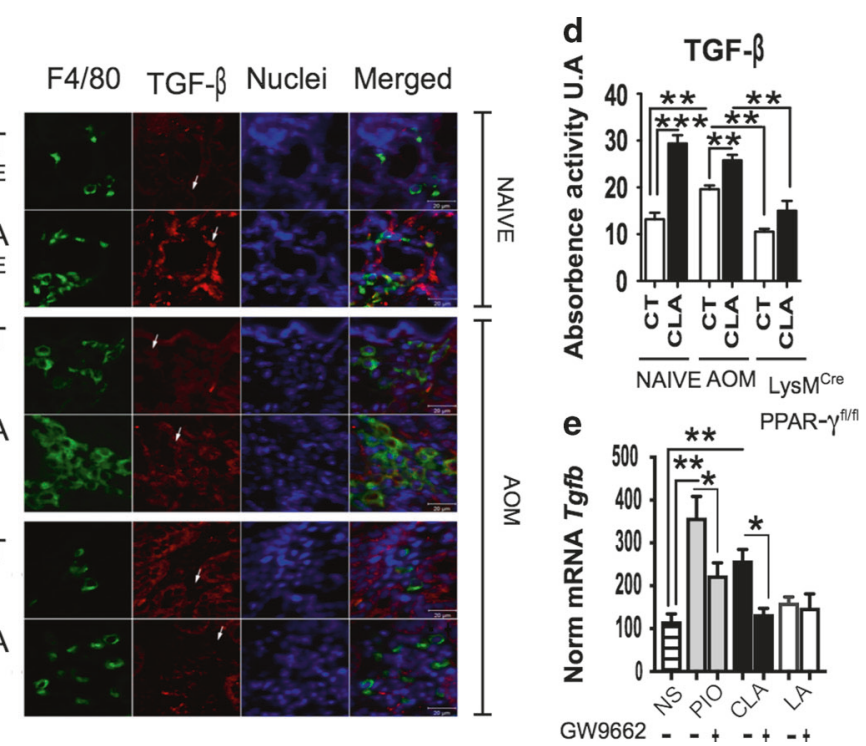

Fig. 4 CLA induces TGF- $\beta$ in macrophages via PPAR- $\gamma$. Littermate and LysM ${ }^{\text {Cre PPAR }} \gamma^{\text {flox/flox }}$ mice received control (CT) or $1 \%$ CLAsupplemented diet for 13 weeks; azoxymethane (AOM) $(10 \mathrm{mg} / \mathrm{kg}$, i.p.) and three cycles of $2 \%$ DSS. a Representative slides showing TGF- $\beta$ staining $(\times 60)$ by immunohistochemistry. b Quantification of TGF- $\beta$ found in a. c Colonic samples were stained with anti-F4/80 (green), antiTGF- $\beta$ (red), and DAPI (blue), and analyzed by confocal microscopy. d Quantification of co-expression of TGF- $\beta$ on F4/80 cells. e qPCR of BMDM cultured in the presence of $100 \mu \mathrm{M}$ of pioglitazone (PIO), conjugated linoleic acid (CLA), or linoleic acid (LA) in the presence or absence (NS) of $10 \mu \mathrm{M}$ PPAR- $\gamma$ antagonist GW9662 for $24 \mathrm{~h}$. $N=5-6$ mice/group. Bars represent mean \pm SEM. One-way ANOVA was used. * $p<0.05$, ${ }^{* *} p<0.01,{ }^{* * *} p<0.001,{ }^{* * *} p<0.0001$

dysplastic processes in both, littermate and LysM ${ }^{\mathrm{Cre}} \mathrm{PPAR}-\gamma^{\text {flox/flox }}$ mice fed CT. However, by comparing littermates and LysM ${ }^{\text {Cre }}$ PAR- $y^{\text {flox/flox }}$ mice fed CLA-supplemented diet, we found an evident diminished inflammation. Interestingly, erosion and ulcer areas were present in LysM ${ }^{\text {Cre PPAR }} \gamma^{\text {flox/flox }}$ mice fed CLA. Dysplastic formation and maligner papillary formations were less frequent in CLA-fed littermates when compared to LysM ${ }^{\text {CrepPAR- }}$ $\gamma^{\text {flox/flox }}$ mice fed CLA. This is consistent with the decreased histological score in CLA-fed LysM ${ }^{\text {Cre PPAR- }} \gamma^{\text {flox/flox }}$ mice (Fig. 3k, I). Noteworthy, although LysM ${ }^{\text {Cre PPAR- }} \gamma^{\text {flox flox }}$ mice showed a reduction in tumor formation, CLA-supplemented mice still had more tumors than LysM ${ }^{\text {Cre PPAR }}{ }^{\text {flox/flox }}$ mice fed CT (Fig. 3j), suggesting that other immune cells may be involved in the CLA protumorigenic effect.

CLA induces the production of TGF- $\beta$ by macrophages via PPAR- $\gamma$ TGF- $\beta$ is a multifunctional cytokine that has been associated with immunoregulation and tumor development. ${ }^{36} \mathrm{CLA}$ has been shown to induce TGF- $\beta$ expression in a model of DSSinduced colitis. ${ }^{37}$ Thus, PPAR- $\gamma$ activation by CLA and the consequent TGF- $\beta$ production could be a common mechanism underlying both anti-inflammatory and protumorigenic effects of CLA. To investigate this hypothesis, adult naive C57BL/6 mice received either CLA-supplemented or CT for 3 weeks. Of note, this time-point correlates with the initiation of CAC in the AOM + DSS model. We found that TGF- $\beta$ expression was increased in colonic tissue from mice fed CLA-supplemented diet as compared to CT-fed mice (Fig. 4a, b). Although mice with CAC and fed CT had a higher colonic TGF- $\beta$ expression than naive animals fed $C T, C L A$ supplementation significantly increased TGF- $\beta$ expression. Importantly, deletion of PPAR- $\gamma$ in macrophages (LysM ${ }^{\text {Cre }}$ PPAR- $\gamma^{\text {flox/flox }}$ mice) significantly decreased CLAinduced TGF- $\beta$ expression (Fig. $4 a, b$ ). We confirmed these results by confocal immunofluorescence of the colonic tissue from mice fed either CLA-supplemented or CT with or without CAC. We used F4/80 as a macrophage marker and found colocalization with TGF- $\beta$ after CLA supplementation. Consistent with our immunohistochemistry findings, CLA did not induce
TGF- $\beta$ expression in F4/80+ macrophages from LysM ${ }^{\text {Cre PPAR- }}$ $\gamma^{\text {flox/flox }}$ mice (Fig. 4c, d).

To further investigate the involvement of PPAR- $\gamma$ activation in TGF- $\beta$ upregulation by macrophages, we quantified the expression of TGF- $\beta$ mRNA by qPCR in BMDM stimulated with CLA in the presence or absence of the PPAR- $\gamma$ antagonist GW9662. LA and PIO were used as controls for PPAR- $\gamma$ activation. BMDM stimulated with CLA had increased levels of TGF- $\beta$ mRNA as compared to non-stimulated cells or cells stimulated with LA. CLA-induced TGF$\beta$ mRNA in BMDM was completely dependent on PPAR- $\gamma$ because GW9662 abolished this effect (Fig. 4e). Thus, TGF- $\beta$ production by macrophages via PPAR $-\gamma$ activation had a crucial role in CLA immunoregulatory effects.

CLA induces the production of TGF- $\beta$ by T cells via PPAR- $\gamma$ Our immunohistocheminstry and confocal immunofluorescence images showed that the increase in TGF- $\beta$ expression after CLA supplementation, despite highly correlated with macrophages, were not specific for these cells. Epithelial cells express high levels of PPAR- $\gamma^{38}$ and are involved in colorectal carcinoma development. ${ }^{39}$ However, no difference was found in TGF- $\beta$ protein expression in epithelial cells between mice fed CLA-supplemented and mice fed CT (Supplementary figure 6A). We also investigated epithelial cell-related cytokine mRNAs in sorted epithelial cells from naive mice supplemented with either control or CLA diet and found that CLA supplementation was associated with decreased expression of Tnfa and Tgfb mRNAs, but no difference was observed in I/18 mRNA between cells from control and CLA-fed mice. $\| 16$ and $/ 16$ were not detected in cells from naive mice (Supplementary figure 6B). Nevertheless, TGF- $\beta$ protein expression was significantly lower in epithelial cells than in the lamina propria (Supplementary figure $5 \mathrm{~A}$ ), indicating that lamina propria is the major site of TGF- $\beta$ induction by CLA.

We also detected increased Tgfb mRNA expression in naive $T$ cells cultured in the presence of CLA. This effect was abolished by the PPAR- $\gamma$ antagonist GW9662 (Supplementary figure 7). Because CD4 T cells expressing the membrane-bound form of TGF- $\beta$, the so-called LAP, have been reported to have enhanced 
a
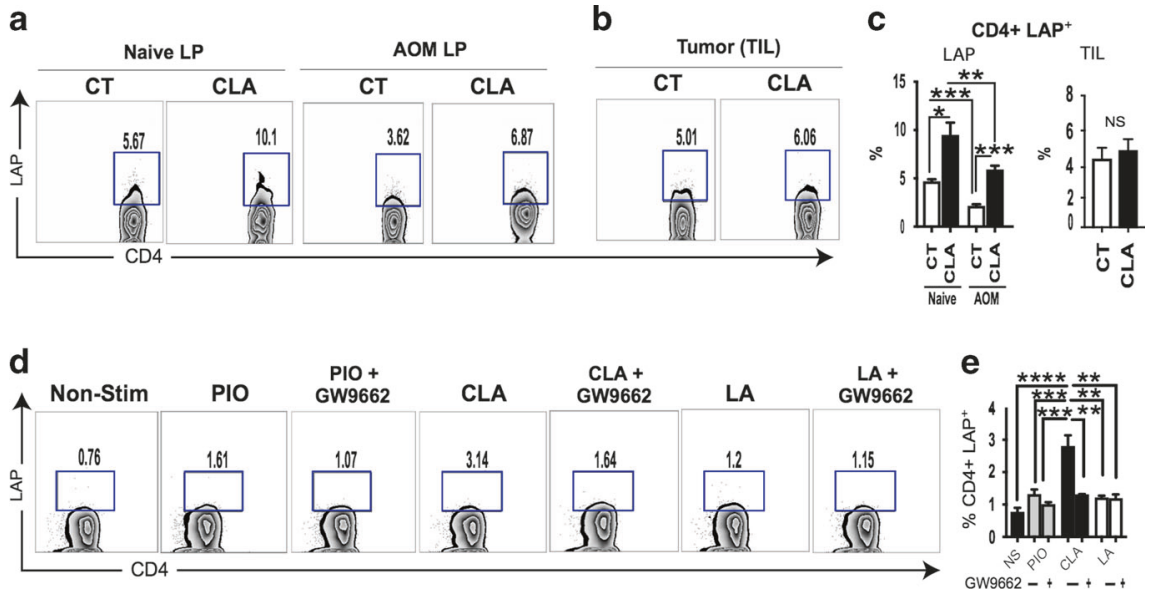

Fig. 5 CLA supplementation induces LAP expression on CD4 T cells. Mice received control (CT) or 1\% CLA-supplemented diet for 13 weeks; azoxymethane (AOM) $(10 \mathrm{mg} / \mathrm{kg}$, i.p.) and three cycles of $2 \%$ DSS. a Colonic lamina propria cells were isolated from naive and AOM-treated mice and stained for LAP for flow cytometric analysis. b Colonic tumors induced by DSS + AOM were isolated and tumor infiltrate

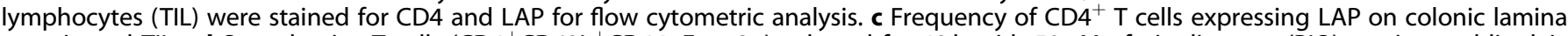
propria and TILs. d Sorted naive T cells $\left(\mathrm{CD} 4^{+} \mathrm{CD} 62 \mathrm{~L}^{+} \mathrm{CD} 44^{-}\right.$Foxp3 $\left.{ }^{-}\right)$cultured for $48 \mathrm{~h}$ with $50 \mu \mathrm{M}$ of pioglitazone (PIO), conjugated linoleic acid (CLA), linoleic acid (LA), or left unstimulated (Non-Stim) in the presence or absence of the PPAR- $\gamma$ antagonist GW9662 (10 $\mu$ M). e Graph representation of LAP expression on $\mathrm{CD}^{+}$cells from $\mathrm{d}$. $N=5$ mice/group. Data are representative of at least three independent experiments. Bars represent mean \pm SEM. One-way ANOVA (c, LAP; e) and Student's $t$ test (c, TIL) were used. NS nonsignificant. ${ }^{*} p<0.05$, ${ }^{* *} p<0.01$, ${ }^{* * *} p<0.001,{ }^{* * * *} p<0.0001$

suppressive activity in colorectal carcinoma patients, ${ }^{25}$ we hypothesized that LAP expression was upregulated after CLA supplementation. Indeed, we found that CLA-fed mice had increased frequency of $\mathrm{CD}^{+} \mathrm{LAP}^{+} \mathrm{T}$ cells in the lamina propria as compared to controls (Fig. $5 \mathrm{a}-\mathrm{C}$ ). No difference in the frequency of $\mathrm{CD}^{+} \mathrm{LAP}^{+}$tumor-infiltrating $\mathrm{T}$ cells between mice fed CLAsupplemented or CT (Fig. 5b). Of note, Foxp3 expression in CD4 $T$ cells was not affected by CLA supplementation (Supplementary figure $8 \mathrm{~A}$ ) and Treg cells cultured in the presence of CLA did not upregulate Tgfb mRNA expression (Supplementary figure 8B). Consistent with this, CLA did not induce Foxp3 expression in naive CD4 $\mathrm{T}$ cells cultured in the presence of CLA (Supplementary figure 7C). Importantly, CLA induced the upregulation of the Treg cell activation markers LAP and CTLA-4 on both total CD4+ T cells and Treg cells (Supplementary figure 9A, B). No difference in the expression of other well-known markers of Treg cells such as GITR, LAG-3, TIM-3, CD103, and CD39 as well as the proliferation marker Ki-67 was observed (Supplementary figure 9A), suggesting that LAP and CTLA-4 play an important role in the immunomodulatory effect of CLA.

To investigate the correlation between LAP induction and PPAR$\gamma$ activation in $\mathrm{CD}^{+} \mathrm{T}$ cells, we sorted naive $\mathrm{CD} 4 \mathrm{~T}$ cells $\left(\mathrm{CD}^{+}{ }^{+} \mathrm{CD}_{2} \mathrm{~L}^{+} \mathrm{CD}_{4} 4^{-}\right.$Foxp3 ${ }^{-}$) from Foxp3-GFP mice and cultured them in the presence of different concentrations of CLA, LA, or PIO. CLA-treated naive cells upregulated LAP, an effect completely abolished by the PPAR- $\gamma$ antagonist GW9662 (Fig. 5d, e).

Taken together, these data indicate that both macrophages and lymphocytes are involved in the immunoregulatory effects of CLA in a mechanism dependent on PPAR- $\gamma$ activation and TGF- $\beta$ production.

Neutralization of LAP decreases both protumorigenic and antiinflammatory effects of CLA

We showed that CLA induced TGF- $\beta$ expression in macrophages and T cells via PPAR- $\gamma$ activation and that this correlated with increased tumor formation. To investigate whether TGF- $\beta$ was indeed responsible for CLA protumorigenic activity, mice receiving either CLA-supplemented or CT were injected with monoclonal anti-LAP antibody for TGF- $\beta$ neutralization during CAC induction, as shown in Fig. 6a. We found that anti-LAP treatment dramatically reduced tumor formation in CAC mice independent of the diet used, confirming the importance of TGF- $\beta$ in tumor development (Fig. 6b). Importantly, LAP neutralization abolished the increase in tumor numbers induced by CLA supplementation as compared to mice fed CT (Fig. 6b-d), suggesting that CLA protumorigenic effect is mediated by TGF- $\beta$-producing cells.

The dual involvement of TGF- $\beta$ in both protumorigenic and anti-inflammatory effects of CLA was further demonstrated by using the anti-LAP antibody in the DSS-induced colitis model. Mice were fed either control or CLA-supplemented diet for 3 weeks and colitis was induced by DSS administration in the drinking water for 7 days. Anti-LAP antibody was injected once a week prior to DSS administration as shown in Fig. 6e. We found that anti-LAP treatment abrogated the anti-inflammatory effect of CLA as shown by body weight loss, shortened colon length, and histological analysis from mice fed CLA and treated with anti-LAP as compared to mice fed CLA and treated with isotype control (IC) antibody (Fig. $6 \mathrm{f}-\mathrm{i}$ ). We cannot rule out the contribution of other anti-inflammatory mediators triggered by CLA through PPAR- $\gamma$, such as eicosanoids, because histological analyzes showed that CLA-fed mice treated with anti-LAP antibody still had some protective effect when compared with CT-fed mice treated with anti-LAP. Nevertheless, our data clearly showed that TGF- $\beta$ release after CLA feeding was important for controlling also the acute inflammation associated with DSS-induced colitis.

\section{DISCUSSION}

CLA is marketed as a dietary supplement in the United States and Europe on the basis of its supposed health benefits. ${ }^{40}$ Even though studies have reported beneficial effects of CLA in animal models of cancer, ${ }^{41}$ atherosclerosis, ${ }^{42}$ and type 2 diabetes, ${ }^{43}$ the mechanisms underlying these effects are still controversial. PPARs, which include PPAR- $\alpha$, PPAR- $\beta / \delta$, and PPAR- $\gamma$, are a group of nuclear receptor proteins that function as transcription factors. ${ }^{44}$ Because of their roles on regulation of cellular differentiation, ${ }^{6}$ metabolism, ${ }^{45}$ and tumorigenesis, ${ }^{46}$ PPARs, particularly PPAR have been implicated as the primary CLA mechanism of action. ${ }^{37}$ Here we showed that CLA supplementation prevented colitis but also contributed significantly for colorectal tumor development in mice. We showed that both anti-inflammatory and protumorigenic properties of CLA were associated with TGF- $\beta$ production 
a

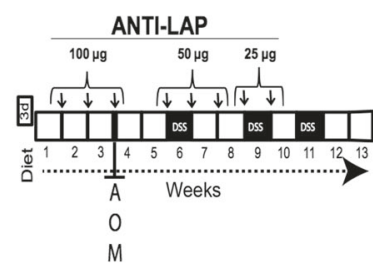

b

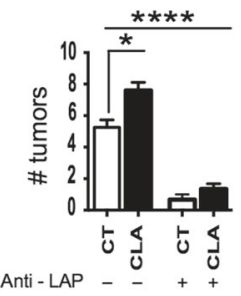

c

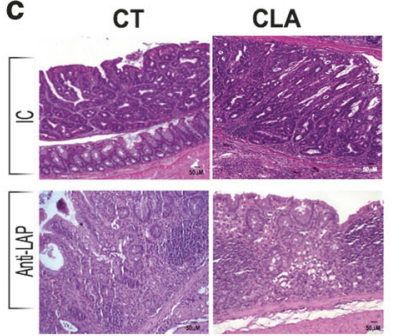

d

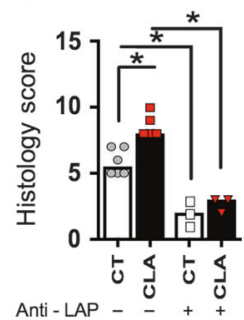

e

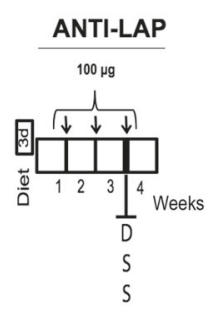

f

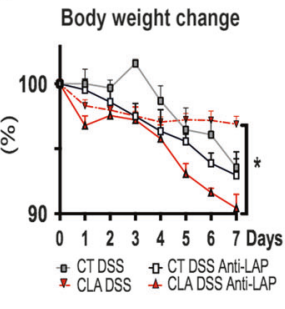

g

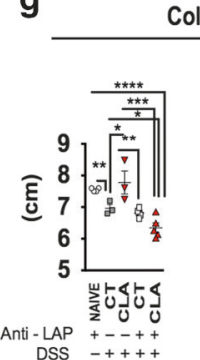

Colon length

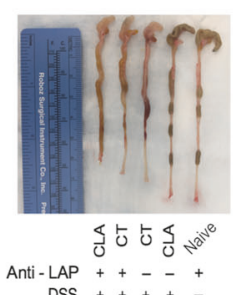

h

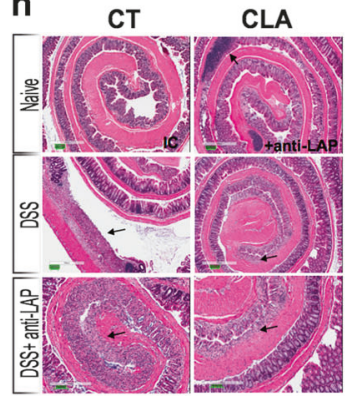

i

Fig. 6 Protumorigenic and anti-inflammatory effects of CLA are prevented by LAP neutralization. Mice received control (CT) or 1\% CLAsupplemented diet for 13 weeks. a Tumor induction protocol using azoxymethane (AOM) + DSS and anti-LAP 100, 50, and $25 \mu \mathrm{g} / \mathrm{mice}$ i.p. b Graph representation of total colonic tumor number. c Adenomas stained with H\&E in colonic tissue $(\times 10)$ in control or CLA-fed mice treated or not with anti-LAP mAb. d Histological numeric scoring system evaluating epithelial and glandular dysplasia, nuclear pleomorphism, and invasion. $N=3$ mice/group. Data are representative of one experiment of two independent experiments. e-i Mice received control (CT) or $1 \%$ CLA-supplemented diet (CLA) for 4 weeks and 2.5\% DSS for 7 days on the fourth week; e anti-LAP treatment time points (100 $\mu$ g/mice); f percentage of body weight change during DSS-induced colitis; $\mathbf{g}$ colon length on DSS-induced colitis; $\mathbf{h} \mathrm{H} \& \mathrm{E}$ colonic section; $\mathbf{i}$ colitis histological numeric scoring system. ND non-detected. $N=5 /$ group. Bars represent the median. Non-parametric Student's $t$ test with Mann-Whitney post-test $(p<0.05)$ was used for histological score. Bars and lines represent mean \pm SEM. Two-way ANOVA was used in f. For others graphs we used one-way ANOVA. \# = statistical difference from all groups ${ }^{* * * *}{ }^{*} p<0.05,{ }^{* *} p<0.01,{ }^{* * *} p<0.001,{ }^{* * * *} p<0.0001$

primarily by macrophages and T cells through PPAR- $\gamma$ activation. Thus, the induction of distinct immunosuppressive cell types can suppress inflammation but also favors tumor escape from immunity control.

Extensive literature has attempted to correlate inflammation and cancer. ${ }^{31}$ It is well known that the failure of the immune system to fight against tumors is one of the most important steps toward cancerous cell evasion. ${ }^{20}$ Importantly, the tumor environment in different types of cancers needs to be carefully considered. In the case of intestinal cancers, it is crucial to take into account many variables that range from the complexity of the gut with several immune structures and compartments to a diverse and constant microbiota and dietary stimulation. ${ }^{47}$ UC patients, for example, have $30 \%$ higher chances to develop CRC than a healthy individual. ${ }^{14}$ On the other hand, inflammation/ cancer relationship is less prominent in patients with Crohn's disease, pointing out for the importance of considering environmental alterations caused by the inflammatory process rather than the inflammation per se. ${ }^{48,49}$ Consistent with this, the CAC model induced by AOM and DSS, which mimics the course of CRC in humans, occurs due to a DNA damage caused by the AOM, associated with an inflammatory/healing process provoked by the alternating cycles of DSS and the consequent immune system activation. ${ }^{50}$ Thus, the apparent dual effect of CLA in the DSSinduced colitis and CAC models is indeed a consequence of its unique immunoregulatory property. Importantly, CRC has a predictable development starting as a benign tumor and slowly progressing to a neoplasia, which is a consequence of a chronic/ inefficient inflammatory process associated with DNA damage. In this context, CLA supplementation and PPAR- $\gamma$ activation would help control/heal inflammation at earlier stages of the disease but would also favor tumor progression at later stages by a common mechanism: the TGF- $\beta$ production. CLA has been shown to exhibit potent antitumor effects in vitro and in murine models of breast cancer, particularly those using immunodeficient mice. In the settings of these studies, CLA anti-tumorigenic activity was found to be independent of the immune system, but rather associated with a pro-apoptotic direct effect in the tumor cells. ${ }^{51,52}$ Therefore, it is likely that a balance between the level of PPAR- $\gamma$ expression in cancer cells versus immune cells will be determinant for the effect of CLA.

It is well known that myeloid rather than lymphoid cells play an important role in the acute inflammatory process caused by DSS administration. ${ }^{53}$ Monocytes/macrophages and neutrophils are major players in this context. ${ }^{28}$ In fact, we showed that PPAR- $\gamma$ activation in macrophages induced by CLA was crucial for CLA immunoregulatory activity, because macrophage-specific deletion of PPAR- $\gamma$ abrogated the anti-inflammatory effect of CLA in the DSS-induced colitis and also prevented mice from developing CAC. More importantly, these effects were mediated by TGF- $\beta$ release upon PPAR- $\gamma$ activation by CLA in macrophages and $T$ cells. TGF- $\beta$ release by macrophages and $T$ cells and the consequent immunoregulatory environment generated could be a common mechanism to explain both anti-inflammatory and protumorigenic properties of CLA in our models. Consistent with this, anti-LAP antibody treatment prior to DSS-induced colitis abrograted the anti-inflammatory effect of CLA.

Our findings that CLA supplementation worsened CAC induced by AOM and DSS contradict a study published by Evans et al. ${ }^{54}$ In this study, authors used a "tissue-specific PPAR- $\gamma$ deletion" (MMTV ${ }^{\text {Cre PPAR- }} \gamma^{\text {flox/flox }}$ mice), in which epithelial and hematopoietic cells lose PPAR- $\gamma$ expression upon Cre recombination, to demonstrate that PPAR- $\gamma$ is crucial for CLA antitumor effects. Thus, as expected, these mice have a broad range of cells that undergo PPAR-y deletion, which can explain the discrepancy between their findings and ours. We showed that both macrophages and T cells specifically contribute to the protumorigenic effect of CLA supplementation, in a mechanism involving TGF- $\beta$ production. 
The role of TGF- $\beta$ in tumor formation and growth is well evidenced in the literature. ${ }^{36}$ Many cancerous cells secrete TGF- $\beta$ in order to induce an immunoregulatory environment and escape from the host's immune system. ${ }^{22}$ Treg cells, particularly those expressing the membrane-bound TGF- $\beta$ (LAP), have been shown to be 50 -fold more suppressive than the classic Foxp3-expressing Tregs in CRC patients. ${ }^{25}$ Consistent with this, it has been reported that increased plasma and tissue levels of TGF- $\beta$ in CRC patients are associated with early metastasis and poor prognosis. ${ }^{55}$ We found that CLA supplementation increased LAP and CTLA-4, but not Foxp3 expression on CD4+Foxp3+ Treg cells, suggesting that CLA induces a more suppressive Treg cell in the colonic mucosa. Moreover, this effect was associated with PPAR- $\gamma$ activation in $T$ cells because naive CD4 T cells cultured in the presence of CLA upregulated LAP (but not Foxp3), which was abolished by the PPAR- $\gamma$ antagonist GW9662. Importantly, in vivo neutralization of TGF- $\beta$ by administering a monoclonal antibody against LAP completely prevented CLA protumorigenic effects. Of note, TGF- $\beta$ neutralization induced a much more robust antitumor effect than conditional deletion of PPAR- $\gamma$ in macrophages, confirming the potent effect of TGF- $\beta$ in promoting tumor development. ${ }^{56}$ These results are consistent with our recent publication showing that anti-LAP treatment blocked the development of several cancer models, including glioblastoma multiform, melanoma, and CAC induced by AOM and DSS. ${ }^{57}$

In summary, we showed that a dietary fatty acid supplementation (CLA) induces TGF- $\beta$ production via PPAR- $\gamma$ activation in macrophages and T cells. These results send a word of caution on the use of an anti-inflammatory dietary supplements that induce immunoregulation in individuals with chronic gastrointestinal inflammation, such as IBD. Because IBD diagnosis and treatment are frequently established many years after the inflammation starts, CLA supplementation may become a potent contributor for tumor development.

\section{METHODS}

Animals and diet

Female C57BL/6 mice at 8 weeks of age were supplied by the Central Animal Facility of Universidade Federal de Minas Gerais (UFMG). Mice were kept in a conventional, pathogen-free experimental animal facility of Laboratório de Imunobiologia, Instituto de Ciências Biológicas, UFMG. All animal procedures were approved by the University Ethical Committee for Animal Experimentation (CETEA-UFMG) Protocol n. 241/2008, and Protocol n. 116/2010. LysM ${ }^{\text {Cre PPAR }}{ }^{\text {flox/flox }}$ mice were generated and kept in Department of Biochemistry and Molecular Biology, University of Debrecen, Medical and Health Science Center, Hungary. C57BL/6 Foxp3-GFP mice were generated and kept at Ann Romney Center for Neurologic Diseases-Brigham and Women's Hospital, Boston, MA, USA. CX3CR1-GFP mice were gently donated by Dr. Israel Charo (Cardiovascular Research Institute, Israel) and Dr. Gustavo Menezes (Morphology Department at UFMG, Brazil). IL-10-deficient (IL-10 ${ }^{-/-}$) mice on a $129 \mathrm{~Sv} /$ Ev background were obtained from Donna-Marie McCafferty's Laboratory (Calgary University, Calgary, Canada). All mice were kept in a controlled environment room $\left(21^{\circ} \mathrm{C}, 55 \% \mathrm{RH}\right)$ with a $12-\mathrm{h}$ light-dark cycle. Mice were separated into two weight-matched groups contaning approximately five mice each. The $C T$ group received AIN93-G ${ }^{58}$ standard diet and CLA diet group (CLA) received AIN93-G diet supplemented with 1\% CLA (Tonalin TG80) kindly provided by BASF (Florham Park, New Jersey) company. Both groups received 3 days of standard diet as an adaptive period. After 3 days, diets were changed every 2-3 days and mice were weighted twice a week. II-10 ${ }^{-1-}$ mice were supplemented with respective control and CLA diet after weaning and were sacrificed at 16 weeks of age.
DSS-induced colitis and AOM/DSS CRC model

Colonic inflammation was induced by the addition of $1.5-2.0 \%(\mathrm{w} /$ v) DSS (40 kDa, MP Biomedicals) in drinking water for 7 days until sacrifice. Naive group received drinking water only. Mice had unlimited access to food during the experiment. DSS consumption was measured and changed daily. To induce tumors, after 3 weeks of diet supplementation, mice were treated with $10 \mathrm{mg} / \mathrm{kg}$ of AOM (Sigma-Aldrich Co.) administered i.p. on day 21. A week later, mice were treated with three cycles of 1 week $1.5 \%$ DSS in the drinking water, followed by weeks of normal drinking water. At the end of the last DSS cycle, drinking water was resumed until the termination of the experiment. After 13 weeks, mice were sacrificed, and tumor number and size measured. Alcian-blue was applied to the colon to help tumor visualization. Tumor size was measured using a paquimeter (Starrett ${ }^{\oplus}$ ).

\section{Macroscopic analysis of Colitis (DAl)}

DSS-induced colitis was assessed macroscopically by scoring three major clinical signs: weight loss, diarrhea, and rectal bleeding at the sacrifice as described by McHenga et al. ${ }^{59}$ Body weight loss was calculated as the difference between the initial and actual weight. Diarrhea was determined by assessing mucus/fecal material adhering to anal fur and was confirmed by the presence or absence of fecal pellet formation and continuous fecal fluid material in the colon. Rectal bleeding was defined as diarrhea containing visible blood and gross rectal bleeding. The three major clinical signs (weight loss, diarrhea, and occult/gross bleeding) were scored separately. The macroscopic score was calculated from the score of the clinical signs using the following formula: (weight loss score) + (diarrhea score) + (rectal bleeding score). Colon were measured with a regular rule.

Colonic tissue enzyme-linked immunosorbent assay for IL-4 and IL-10 detection

Colon samples were weighted and homogenized (Omni, Lodan ${ }^{\oplus}$ ) in phosphate-buffered saline (PBS) containing protease inhibitor $(0.1 \mathrm{mg} / \mathrm{ml}$ trypsin inhibitor aprotinin, $50 \mathrm{mM}$ EDTA, and $1 \mathrm{mM}$ phenylmethylsulfonyl fluoride in PBS). For each $100 \mathrm{mg}$ of tissue, $1 \mathrm{ml}$ of buffer was added. Suspensions were centrifuged at 12 $000 \times g$ for $20 \mathrm{~min}$ at $4{ }^{\circ} \mathrm{C}$ and supernatants were transferred into clean Eppendorf tubes and stored at $-80^{\circ} \mathrm{C}$ until analysis. Concentration of IL-4 and IL-10 was measured by enzyme-linked immunosorbent assay (ELISA). Briefly, supernatants were added to microtitre plates (Nunc), previously coated with purified monoclonal antibodies reactive to IL-4 and IL-10 (BD Bioscience). Standards and samples were added and incubated overnight at $4^{\circ}$ C. Biotinylated monoclonal antibodies (BD Bioscience) were added and incubated for $1 \mathrm{~h}$ at room temperature, followed by peroxidase-labeled streptavidin (Sigma-Aldrich Co.). Color reaction was developed at room temperature with $100 \mu \mathrm{l} /$ well of orthophenylenediamine (Sigma-Aldrich Co.) $(1 \mathrm{mg} / \mathrm{ml}), \quad 0.04 \% \quad \mathrm{H}_{2} \mathrm{O}_{2}$ substrate in sodium citrate buffer. Reaction was interrupted by the addition of $20 \mu \mathrm{l} /$ well of $2 \mathrm{~N} \mathrm{H}_{2} \mathrm{SO}_{4}$. Absorbance was measured at $490 \mathrm{~nm}$ by an ELISA reader (Bio-Rad Model 450 Microplate Reader).

\section{Gut permeability}

Mice had food and water removed $4 \mathrm{~h}$ prior to the oral administration of fluorescein isothiocyanate (FITC)-dextran [60 $\mathrm{mg} / 100 \mathrm{~g}$ body weight, average mol wt 4,000; Sigma-Aldrich Co.)]. Serum was collected by cardiac puncture $4 \mathrm{~h}$ later and the fluorescence intensity of each sample measured (excitation, 492 $\mathrm{nm}$; emission, $525 \mathrm{~nm}$; Spectromax M3, Molecular Devices Inc., Sunnyvale, CA, USA). FITC-dextran concentrations were determined using standard curves generated by serial dilution of FITC-dextran. Permeability was expressed as relative absorbance. 
196

\section{Secretory $\lg \mathrm{A}$}

Small intestines were washed with $10 \mathrm{ml}$ of cold PBS. The suspensions were centrifuged at $12000 \times g$ for $20 \mathrm{~min}$ at $4{ }^{\circ} \mathrm{C}$, and the levels of $\operatorname{Slg} A$ in the supernatant were determined by ELISA as previously described by Santos Rocha et al. ${ }^{60}$ Briefly, supernatants were added to microtitre plates (Nunc), previously coated with purified monoclonal antibodies reactive to Ig (BD Bioscience). Standards and samples were added and incubated overnight at $4{ }^{\circ} \mathrm{C}$. Biotinylated monoclonal antibodies (BD Bioscience) anti-lgA were added and incubated for $1 \mathrm{~h}$ at room temperature, followed by peroxidase-labeled streptavidin (SigmaAldrich Co.). Color reaction was developed at room temperature with $100 \mu \mathrm{l} /$ well of orthophenylenediamine (Sigma-Aldrich Co.; 1 $\mathrm{mg} / \mathrm{ml}$ ), $0.04 \% \mathrm{H}_{2} \mathrm{O}_{2}$ substrate in sodium citrate buffer. Reaction was interrupted by the addition of $20 \mu \mathrm{l} /$ well of $2 \mathrm{~N} \mathrm{H}_{2} \mathrm{SO}_{4}$. Absorbance was measured at $490 \mathrm{~nm}$ by an ELISA reader (Bio-Rad Model 450 Microplate Reader).

\section{NAG and MPO activity measurement}

Colonic tissue was weighted and homogenized with PBS and centrifuged at $12000 \times g$ for $10 \mathrm{~min}$. The supernatant was discarded, and the erythrocytes were lysed. Samples were then centrifuged, the supernatant was discarded, and the pellet was resuspended in $1.9 \mathrm{ml}$ of $0.5 \%$ hexadecyltrimethyl ammonium bromide in PBS, frozen three times in liquid nitrogen, and centrifuged at $4^{\circ} \mathrm{C}$ at $12000 \times g$ for $10 \mathrm{~min}$. The supernatant was used in the enzymatic assays. On thawing and processing, the tissue was assayed for MPO activity by measuring the change in optical density at $450 \mathrm{~nm}$ using tetramethylbenzidine and the NAG by $\mathrm{N}$-acetilglicosaminidase (Sigma-Aldrich $\mathrm{Co}$.). Results were expressed as the relative unit that denotes activity of each enzyme related with each experimental group.

\section{Colitis and CAC histopathology}

Colon samples from water and DSS-treated mice were fixed with a PBS solution containing 4\% paraformaldehyde and then embedded in paraffin. Five micrometers of paraffin blocks were cut and stained with hematoxylin and eosin. For colitis histological inflammation scoring, colon tissues were observed under a microscope (Olympus, BX40) and sections were scored blindly by an expert. Histological scoring was based on a semiquantitative scoring system considering inflammatory infiltrate, edema, and reepithelization. Data were presented as frequency of slides showing each parameter. Yellow, red, and green represent the intensity. In LysM ${ }^{\text {Cre PPAR }}$ flox/flox $^{\text {mice }}$ and IL-10-/- mice experiments, we used a score system described by McCafferty et al. ${ }^{61}$ in which the following features were graded: extent of destruction of normal mucosal architecture $(0$, normal; 1,2 , and 3, mild, moderate, and extensive damage, respectively), presence and degree of cellular infiltration (0, normal; 1, 2, and 3, mild, moderate, and transmural infiltration, respectively), extent of muscle thickening $(0$, normal; 1,2 , and 3 , mild, moderate, and extensive thickening, respectively), presence or absence of crypt abscesses ( 0 , absent or 1 , present), and presence or absence of goblet cell depletion ( 0 , absent or 1 , present). For CAC histological scoring, colon tissues were observed under a microscope (Olympus, BX40) and analyzed by three different pathologists. Histology score evaluated the epithelium ( 0 , normal; 1 , moderate hyperplasia; 2 , moderate dysplastic; 3 , severe dysplastic), glandular dysplasia nuclear ( 0 , absent; 1 , low; 2 moderate; 3, intense), pleomorphism (0, absent; 1 , low; 2, moderate; 3, intense), and muscularis and serosa invasion ( 0 , absent; 1 , present).

Immunohistochemistry for CDC47 and TGF- $\beta$

Consecutive $4-\mu m$-thick sections were obtained and mounted on sialanated slides for immunohistochemical study. Sections were stained for rabbit polyclonal antibodies: TGF- $\beta$ (1:100, Santa Cruz, USA) and CDC47 (MCM7 Ab-2, Thermo Fisher). Heat-induced epitope retrieval (20 min) using Dako antigen retrieval solution, $\mathrm{pH}$ 6.0 (Dako), was previously performed in a water bath. The slides were then cooled to room temperature for $20 \mathrm{~min}$ in the antigen retrieval buffer. The sections were incubated at room temperature in $3 \%$ ( $\mathrm{vol} / \mathrm{vol}) \mathrm{H}_{2} \mathrm{O}_{2}$ for $15 \mathrm{~min}$, in primary antibodies for $16 \mathrm{~h}$, in reagent contained anti-mouse and anti-rabbit secondary antibodies (Biotinylated Goat Anti-polyvalent, Laboratory Vision) for $15 \mathrm{~min}$, and in streptavidin peroxidase (UltraVision Large Volume Detection System, HRP, Laboratory Vision) for $15 \mathrm{~min}$. Between incubations, the slides were washed twice for $5 \mathrm{~min}$ in PBS containing $1 \%$ ( $\mathrm{vol} / \mathrm{vol}$ ) Tween 20 . Immunoreactivity was visualized by incubating the slides for $10 \mathrm{~min}$ with diaminobenzidine (DAB Substrate System; Laboratory Vision). The slides were then counterstained with Harris hematoxylin. Positive and negative control slides were included in each batch. Negative controls were assessed using normal serum (Ultra V Block, Laboratory Vision) as the primary antibody. Percentage of positive cells in 500 cell/field was considered to quantitative results.

\section{Confocal microscopy}

Immunofluorescence was performed as previously described by Rodrigues et al. ${ }^{62}$ In brief, colonic tissue sections were dewaxed, rehydrated, and unmasked in trilogy solution (Cell Marque, Koclin, CA, USA) in pressurized heating $\left(125^{\circ} \mathrm{C}\right)$ during 20 min per the manufacturer's instructions. Next, samples were rinsed in PBS (137 $\mathrm{mM} \mathrm{NaCl}, 2.7 \mathrm{mM} \mathrm{KCl}$, and $10 \mathrm{mM}$ phosphate buffer solution, $\mathrm{pH}$ 7.4) (Sigma-Aldrich Co.) and then incubated in PBS containing $0.2 \%$ Triton X-100 (Sigma-Aldrich Co.) for another $20 \mathrm{~min}$ and blocked in PBS containing $1 \%$ bovine serum albumin (BSA; SigmaAldrich Co.) for $30 \mathrm{~min}$. The sections were next incubated with a mouse monoclonal antibody against F4/80 (1:100, Santa Cruz, USA) and a rabbit polyclonal antibody against TGF- $\beta$ (1:100, Santa Cruz, USA) overnight at $4{ }^{\circ} \mathrm{C}$, then rinsed three times for $5 \mathrm{~min}$ in PBS. Subsequently, sections were incubated with Alexa Fluor 488 Goat Anti-Rabbit IgG antibody (1:1000, Life Technologies), Alexa Fluor 555 Goat anti-mouse lgG antibody (1:1000, Life Technologies), and Hoechst 33258 (1 g/ml, Life Technologies) for $1 \mathrm{~h}$ at room temperature. Next, samples were washed three times in PBS for $10 \mathrm{~min}$ and then mounted in Prolong Gold Anti fade reagent (Life Technologies). The negative control was included in all reactions by omitting primary antibodies. Images were collected using a Zeiss LSM 5 Live or 880 (Carl Zeiss, Jena, Germany). The software Zeiss Efficient Navigation (ZEN) was used for orthogonal projections. The fluorescence microscopy results were evaluated in three areas and five images were collected from each sample using the software ImageJ.

\section{Lamina propria cell extraction}

Lamina propria cells were extracted as described by David et al. ${ }^{63}$ Colon tissue were collected and flipped inside out. Feces and mucus were removed, and tissue was washed several times using Hank's balanced salt solution (HBSS) solution supplemented with $5 \%$ fetal calf serum (FCS) and $25 \mathrm{mM}$ HEPES. After cleaning, colons were incubated for $30 \mathrm{~min}$ at $37^{\circ} \mathrm{C}$ in a shaker with HBSS (Gibco) supplemented with 15 mM HEPES (Sigma) + 5 mM EDTA (Neon) + $10 \%$ FCS (Gibco) $+0.015 \%$ or $1 \mathrm{mM} 1.4$-dithiothreitol (DTT; SigmaAldrich Co.). After incubation, tissues were washed three times with HBSS solution supplemented with $2 \mathrm{mM}$ EDTA and $25 \mathrm{mM}$ HEPES. Tissues were chopped in smaller pieces and incubated with Ex-vivo (Lonza) containing Liberase TL (Roche) $5 \mathrm{mg} / 80 \mathrm{ml}+$ Dnase $30 \mu \mathrm{g} / \mathrm{ml}$ (Sigma-Aldrich Co.) for $1 \mathrm{~h}$ in a $37^{\circ} \mathrm{C}$ shaker. The supernatant containing lamina propria cells was meshed using a 40 and $100 \mu \mathrm{m}$ cell strainer and washed with HBSS solution supplemented with $2 \mathrm{mM}$ EDTA and $25 \mathrm{mM}$ HEPES. Cell suspension was obtained by resuspension cell in RPMI or fluorescence-activated cell sorting (FACS) buffer containing BSA (Sigma-Aldrich Co.). To obtain tumor-infiltrating lymphocytes, similar protocol was applied using collected colonic tumors. 
Colonic epithelial cell extraction

Epithelial cells were extracted as described by Magness et al. ${ }^{64}$ with modifications. Colonic tissue was collected, and feces and mucus were removed. Colon tissue and flipped inside out and tissue was washed several times using HBSS solution supplemented with $5 \%$ FCS and $25 \mathrm{mM}$ HEPES. Colon were incubated for $30 \mathrm{~min}$ at $37^{\circ} \mathrm{C}$ in a shaker with HBSS (Gibco) supplemented with $15 \mathrm{mM}$ HEPES (Sigma) +5 mM EDTA (Neon) $+10 \%$ FCS (Gibco) $+0.015 \%$ or $1 \mathrm{mM}$ DTT (Sigma-Aldrich Co.). After incubation, supernatant (I) was collected and tissues were incubated again with $30 \mathrm{mmol} / \mathrm{I} \mathrm{EDTA}$ in HBSS at $37^{\circ} \mathrm{C}$ for $8 \mathrm{~min}$. Supernatant (II) was pooled with supernatant (I) and centrifugated. Cell pellet was washed once using modified HBSS. The cells were then incubated in $10 \mathrm{ml}$ of modified HBSS containing $0.3 \mathrm{U} / \mathrm{ml}$ of dispase (Roche, San Francisco, CA) at $37^{\circ} \mathrm{C}$ for $10 \mathrm{~min}$ to dissociate epithelial sheets to single cells. To enhance cell viability and decrease cell clumping, $1 \mathrm{ml}$ of FBS and $1000 \mathrm{U}$ DNase I (Roche) were added to cell suspension, which was sequentially passed through 70 and $40-\mu \mathrm{m}$ filters (BD Falcon, Bedford, MA). Cells were pelleted, then resuspended in HBSS to inactivate the Dispase. Epithelial cells were stained with conjugated monoclonal antibodies (mAbs) to Lin-(CD45 allophycocyanin (APC), 7-AAD, CD19, CD3, Nk1.1, and Ly-6G PerCP) and EPCAM-FITCconjugated. Cells were sorted were (FACS Aria II, BD Bioscience) using DIVA software (BD Bioscience) and resuspended in lysis buffer for RNA extraction. RNA was extracted with miRNAeasy as showed in Gene Expression by $\mathrm{qPCR}$ section in respective method. Mm01336189 Il1 $\beta$, Mm00443258_m1 Tnfa, Mm00446190_m1 Il6, Mm00434226_m1 Il18, (Mm00441724_01) Tgfß.

Antibodies and flow cytometric analysis

FITC-conjugated mAbs to Foxp3, F4/80, and Ki-67; Alexa Fluor 488conjugated $\mathrm{mAbs}$ to $\mathrm{CD} 25$; phycoerithrin (PE)-conjugated mAbs to LAP, CD124, CTLA-4, and CD39; PercP-conjugated mAbs to CD11b, CD4, and 7-AAD; APC-conjugated CD206, LAG-3, and CD45; (Pecy7)-conjugated GITR and TIM-3; Brillant Violet (BV421)-conjugated CD103 and LAP; and Fixable Viability Dye Fluor 506 were purchased from eBioscience. Surface staining was performed according to standard procedures at a density of $0.5-1 \times 10^{6}$ cells/ $25 \mu \mathrm{l}$, and volumes were scaled up accordingly. Flow cytometric analysis was performed on a FACScalibur and FACScanto (BD Biosciences) with the use of FlowJo software (Tree Star Inc). For Foxp3 intracellular staining, the Foxp3 staining kit from eBioscience kit was used as per manufacturer's instructions. Fluorescence minus one was used as a parameter to identify gating strategy.

\section{Luciferase assay}

AD239T cells were transfected with gene reporter constructs along with plasmids encoding $\beta$-galactosidae and full-length receptors in triplicates using poliethylenimine and DNA was purified using the Medprep Kit (Roche). Six hours after transfection, cells were exposed to ligands. After $48 \mathrm{~h}$ of incubation, luciferase activity was determined by Luciferase Assay System (Promega) and normalized to $\beta$-galactosidase activity.

In vitro assay for macrophages

Peritoneal macrophages were harvested 4 days after i.p. injection of $2.0 \mathrm{ml}$ of $3 \%$ thioglycolate medium (Difco) to 8 weeks' C57BL/6 mice. Cells were plated in $96-\left(1 \times 10^{5}\right.$ cells/well $), 24-\left(3 \times 10^{5}\right.$ to $1 \times 10^{6}$ cells/well), or 6 -well plates $\left(5 \times 10^{6}\right.$ cells/well $)$ containing RPMI 1640 (Gibco) supplemented with $10 \%$ of heat-inactivated FBS (Cripion Biotecnologia Ltda) and $50 \mathrm{mg} / \mathrm{ml}$ of gentamycin (Shering-Plough) (RPMI/FBS) and incubated for $2 \mathrm{~h}$ at $37^{\circ} \mathrm{C}$ and $5 \%$ $\mathrm{CO}_{2}$. Adherent cells were then washed with RPMl, further incubated overnight under the same conditions, and the medium was replaced by a fresh one. Unless otherwise indicated, cells were cultured in the presence of CLA, PIO (Sigma-Aldrich Co.), LA (Sigma-Aldrich Co.), and GW9662 (Sigma-Aldrich Co.). Bone marrow macrophages were obtained by flushing femurs and tibias with $5 \mathrm{ml}$ of HBSS (Life Technologies do Brasil). Cells were purified using Ficoll-Paque (Amersham Biosciences, Arlington Heights, IL). The suspension was centrifuged, and cells were resuspended in RPMI/FBS containing 30\% L929 for 5 days. Twentyfour-well plates were incubated at $37^{\circ} \mathrm{C}$ and $5 \% \mathrm{CO}_{2}$. Cells were used on the fifth day of culture, when completely differentiated into macrophages.

Gene expression by qPCR

RNA was extracted with miRNAeasy kit (Qiagen) following the manufacturer's protocol, including the optional on-column DNase Digestion step. CDNA was prepared by using the ReverseTranscription PCR Kit following the manufacturer's instructions (Applied Biosystems) and used for qPCR. Results were normalized to Rpl19 (Mm02601633_g1) or Gapdh (Mm99999915_g1). All TaqMan primers and probes were from Applied Biosystems and were used on the ViiA 7 Real-Time PCR System (Applied Biosystems). Tgf- $\beta 1$ (Mm00441724_01), PPAR-훽 (Mm00440940_m1).

\section{Western blot}

Total cellular proteins were isolated using standard methods described by Oliveira et al. ${ }^{65}$ In brief, cell monolayers were washed with PBS and treated with lysis buffer (50 mM Tris- $\mathrm{HCl}, \mathrm{pH} 7.4,150$ $\mathrm{mM} \mathrm{NaCl}, 50 \mathrm{mM} \mathrm{NaF}, 10 \mathrm{mM} \beta$-glycerophosphate, $0.1 \mathrm{mM}$ EDTA, $10 \%$ glycerol, $1 \%$ Triton $\mathrm{X}-100$, and $1 \mathrm{mM}$ sodium orthovanadate) supplemented with a protease inhibitor cocktail (GE Healthcare). The lysates were then clarified by centrifugation at $13000 \times g$ for $10 \mathrm{~min}$ at $4^{\circ} \mathrm{C}$ and the protein concentrations of the whole-cell lysates were measured by the Bradford protein assay (BioRadlaboratories, Inc.). Lysates of the same number of cells (around $40 \mathrm{mg}$ protein) were subjected to electrophoresis on SDSpolyacrylamide gel electrophoresis gels followed by western blot according to standard techniques, using the following monoclonal antibodies: anti-PPAR- $\gamma$ and anti- $\beta$-actin (Cell Signaling Technology Inc.). Peroxidase-labeled anti-rabbit lgG (KPL) was used as the secondary antibody. Immunoreactive bands were visualized using a Luminol chemiluminescent HRP substrate (Millipore) and were analyzed in a Storm System 860 (GE Healthcare). Densitometry analyses were performed using ImageJ.

\section{In vitro T-cell assay for LAP detection}

Naive T cells $\left(\mathrm{CD}_{4}^{+} \mathrm{CD} 2 \mathrm{~L}^{+} \mathrm{CD} 44^{-} \mathrm{Foxp}^{-}\right)$were sorted from from Foxp3-GFP mice (FACS Aria II, BD Bioscience). Cells $\left(1 \times 10^{5}\right.$ cells/ well) were placed in 96-well plate and cultured in the presence of $\mathrm{CLA}(10,25,50$, and $100 \mu \mathrm{l}), \mathrm{PIO}$ (10 and $100 \mu \mathrm{l}$; Sigma-Aldrich Co.), LA (Sigma-Aldrich Co.), and GW9662 (10 and $100 \mu \mathrm{l}$; Sigma-Aldrich Co.) Cells were incubated at $37^{\circ} \mathrm{C} / 5 \% \mathrm{CO}_{2}$. After $24 \mathrm{~h}$, cells were stained with eFluor780 fixable viability dye, PerCP-anti-CD4 (RM45), and BV421-anti-LAP (TW7-16B4) for flow cytometry analysis. Acquisition was performed on LSRII (BD Bioscience) using DIVA software (BD Bioscience).

In vitro T-cell assay for PPAR- $\gamma$-related genes Cpt1a and Tgfb Naive $\mathrm{T}$ cells $\left(\mathrm{CD} 4^{+} \mathrm{CD}_{2} \mathrm{~L}^{+} \mathrm{CD}_{4} 4^{-} \mathrm{Foxp}^{-}\right)$and Treg cells $\left(\mathrm{CD}^{+}{ }^{+} \mathrm{Foxp}^{+}\right)$were sorted from from Foxp3-GFP mice (FACS Aria II, BD Bioscience). Cells $\left(1 \times 10^{5}\right.$ cells/well) were placed in 96 -well plate and cultured in the presence of CLA (50 $\mu \mathrm{M}$ Nu-check) and GW9662 $(10 \mu \mathrm{M}$; Sigma-Aldrich Co.) Cells were incubated at $37^{\circ} \mathrm{C} / 5 \% \mathrm{CO}_{2}$. After $48 \mathrm{~h}$, cells were lysed, and RNA was extracted with miRNAeasy as showed in Gene Expression by qPCR section in respective method. Results were normalized to GAPDH (Mm99999915_g1). Cpt1a (Mm01231183_m), Tgf $\beta$ (Mm00441724_01).

\section{Anti-LAP treatment}

Mice were treated with either anti-LAP or IC mAbs prepared in PBS. Mouse anti-LAP monoclonal antibodies were isolated from 
hybridoma generated in-house. The clone employed for in vivo treatments was TW7-16B4 (IgG1). ${ }^{57}$ Respective isotype-matching controls were purchased from BioXCell. As a standard treatment, antibodies were administered by i.p. injections in different quantities and time points accordingly.

\section{Statistical analysis}

Results are presented as the mean values standard error mean ( \pm SEM) from groups of at least four animals for each condition and considered statistically significant when comparisons between groups, using Student's $t$ test, one-way or two-way analysis of variance $P$-values were $<0.05$. For histological scores, we used medians and non-parametric Student's $t$ test with Mann-Whitney post-test. ${ }^{*} p<0.05,{ }^{* *} p<0.01,{ }^{* * *} p<0.001,{ }^{* * * *} p<0.0001$.

\section{ACKNOWLEDGEMENTS}

We would like to acknowledge Marie Curie fellowship program, and Nuclear Receptor-network EU-funded project for supporting collaboration projects. We are thankful to BASF company for kindly provide Tonalin , to Dr. Dezső Balázs from Pathology Department from Debrecen University, Hungary for the kind help with pathology discussions and slides manufacture. We are also grateful to Dr. Vany Ferraz from Chemistry Department of UFMG, Brazil for providing CG analysis of CLA diet, to Dr. Denise Carmona (UFMG, Brazil), and Dr. Claudia Martins Carneiro (UFOP, Brazil) for discussion and pathological analysis. This study had financial support from Conselho Nacional de Desenvolvimento Científico e Tecnológico, Brazil (CNPq) and Fundação de Amparo a Pesquisa do Estado de Minas Gerais, Brazil (FAPEMIG).

\section{AUTHOR CONTRIBUTIONS}

T.G.M. designed the project and experiments, carried out the experiments, and wrote the manuscript. L.S.H. set up CAC model and helped perform experiments; A.C.G. helped designed the project and performed experiments; R.P.O. provided input for experiment design; N.M.G.P.Q. performed western blot experiments; D.M. performed epithelial cell-related experiments and qPCR; B.D. helped perform luciferase assays; A. T.V. performed gut permeability; S.L. performed DSS experiment in anti-LAP treatment; M.A.R. performed confocal immunofluorescence microscopy, D.A.G. performed confocal analysis, G.G. designed anti-LAP experiments and provide the antibody; E.F. performed IHC and histology experiments and analysis; H.L.W. provide anti-LAP antibody and reagents, R.M.R. performed experiments and wrote the manuscript. L.N. supervised PPAR- $\gamma$ experiments, provided LysM ${ }^{\text {Cre }}$ PPAR- $\gamma^{\text {flox/flox }}$ mice, helped design experiments, and corrected manuscript; A.M.C.F. supervised the project, designed experiments, and corrected the manuscript.

\section{ADDITIONAL INFORMATION}

The online version of this article (https://doi.org/10.1038/s41385-018-0090-8) contains supplementary material, which is available to authorized users.

Competing interests: The authors declare no competing interests.

\section{REFERENCES}

1. Pariza, M. W. et al. A beef-derived mutagenesis modulator inhibits initiation of mouse epidermal tumors by 7,12-dimethylbenz[a]anthracene. Carcinogenesis 6, 591-593 (1985).

2. Banni, S. et al. Conjugated linoleic acids (CLA) as precursors of a distinct family of PUFA. Lipids 39, 1143-1146 (2004).

3. Gholami, Z. \& Khosravi-Darani, K. An overview of conjugated linoleic acid: microbial production and application. Mini Rev. Med. Chem. 14, 734-746 (2014).

4. Turpeinen, A. M. et al. Bioconversion of vaccenic acid to conjugated linoleic acid in humans. Am. J. Clin. Nutr. 76, 504-510 (2002).

5. Dussault, I. \& Forman, B. M. Prostaglandins and fatty acids regulate transcriptional signaling via the peroxisome proliferator activated receptor nuclear receptors. Prostaglandins Other Lipid Mediat. 62, 1-13 (2000).

6. Szanto, A. et al. STAT6 transcription factor is a facilitator of the nuclear receptor PPARY-regulated gene expression in macrophages and dendritic cells. Immunity 33, 699-712 (2010).

7. Mansén, A., Guardiola-Diaz, H., Rafter, J., Branting, C. \& Gustafsson, J. A. Expression of the peroxisome proliferator-activated receptor (PPAR) in the mouse colonic mucosa. Biochem. Biophys. Res. Commun. 222, 844-851 (1996).
8. Bassaganya-Riera, J. et al. Conjugated linoleic acid modulates immune responses in patients with mild to moderately active Crohn's disease. Clin. Nutr. 31, 721-727 (2012).

9. Belury, M. A. Inhibition of carcinogenesis by conjugated linoleic acid: potential mechanisms of action. J. Nutr. 132, 2995-2998 (2002).

10. Rousseaux, $C$. et al. The 5-aminosalicylic acid antineoplastic effect in the intestine is mediated by PPARY. Carcinogenesis 34, 2580-2586 (2013).

11. Dubuquoy, L. et al. Impaired expression of peroxisome proliferator-activated receptor gamma in ulcerative colitis. Gastroenterology 124, 1265-1276 (2003).

12. Dubuquoy, L. et al. PPARgamma as a new therapeutic target in inflammatory bowel diseases. Gut 55, 1341-1349 (2006).

13. Bertin, B., Dubuquoy, L., Colombel, J.-F. \& Desreumaux, P. PPAR-gamma in ulcerative colitis: a novel target for intervention. Curr. Drug. Targets 14, 1501-1507 (2013)

14. Rogler, G. Chronic ulcerative colitis and colorectal cancer. Cancer Lett. 345 , 235-241 (2014).

15. Bernstein, C. N. Large registry epidemiology in IBD. Inflamm. Bowel Dis. 23, 1941-1949 (2017).

16. Matuchansky, C. Cancer colorectal: quelques aspects actuels de son épidémiologie, de sa prévention et de son dépistage. Presse Med. 46, 141-144 (2017).

17. Duricova, D. What can we learn from epidemiological studies in inflammatory bowel disease? Dig. Dis. 35, 69-73 (2017).

18. Luo, C. \& Zhang, H. The role of proinflammatory pathways in the pathogenesis of colitis-associated colorectal cancer. Mediat. Inflamm. 2017, 1-8 (2017)

19. Tanaka, T. et al. A novel inflammation-related mouse colon carcinogenesis model induced by azoxymethane and dextran sodium sulfate. Cancer Sci. 94, 965-973 (2003).

20. Grivennikov, S. I., Greten, F. R. \& Karin, M. Immunity, Inflammation, and Cancer. Cell 140, 883-899 (2010).

21. Erreni, M., Mantovani, A. \& Allavena, P. Tumor-associated macrophages (TAM) and inflammation in colorectal cancer. Cancer Microenviron. 4, 141-154 (2011).

22. Tanaka, A. \& Sakaguchi, S. Regulatory T cells in cancer immunotherapy. Cell Res. 27, 109-118 (2017).

23. Saito, $T$. et al. Two FOXP3 + CD4 $+\mathrm{T}$ cell subpopulations distinctly control the prognosis of colorectal cancers. Nat. Med. 22, 679-684 (2016).

24. Nishikawa, H. \& Sakaguchi, S. Regulatory T cells in cancer immunotherapy. Curr. Opin. Immunol. 27, 1-7 (2014).

25. Scurr, M. et al. Highly prevalent colorectal cancer-infiltrating $\mathrm{LAP}^{+} \mathrm{Foxp}^{-} \mathrm{T}$ cells exhibit more potent immunosuppressive activity than Foxp $3^{+}$regulatory $\mathrm{T}$ cells. Mucosal Immunol. 7, 428-439 (2014).

26. Viladomiu, M., Hontecillas, R. \& Bassaganya-Riera, J. Modulation of inflammation and immunity by dietary conjugated linoleic acid. Eur. J. Pharmacol. 785, 87-95 (2016).

27. Moreira, T. G. et al. Consumption of conjugated linoleic acid (CLA) supplemented diet during colitis development ameliorates gut inflammation without causing steatosis in mice. J. Nutr. Biochem. 57, 238-245 (2018).

28. Sepúlveda, S. E. et al. [Inflammatory bowel diseases: an immunological approach]. Rev. Med. Chil. 136, 367-375 (2008).

29. Ferrante, C. J. et al. The adenosine-dependent angiogenic switch of macrophages to an M2-like phenotype is independent of interleukin-4 receptor alpha (IL4Ra) signaling. Inflammation 36, 921-931 (2014).

30. Medina-Contreras, O. et al. CX3CR1 regulates intestinal macrophage homeostasis, bacterial translocation, and colitogenic Th17 responses in mice. J. Clin. Invest. 121, 4787-4795 (2011).

31. Kraus, S. \& Arber, N. Inflammation and colorectal cancer. Curr. Opin. Pharmacol. 9, 405-410 (2009).

32. Pariza, M. W. \& Ha, Y. L. Conjugated dienoic derivatives of linoleic acid: a new class of anticarcinogens. Med. Oncol. Tumor Pharmacother. 7, 169-171 (1990).

33. Bassaganya-Riera, J. \& Hontecillas, R. CLA and n-3 PUFA differentially modulate clinical activity and colonic PPAR-responsive gene expression in a pig model of experimental IBD. Clin. Nutr. 25, 454-465 (2006).

34. Botta, M. et al. PPAR agonists and metabolic syndrome: an established role? Int. J. Mol. Sci. 19, pii: E1197 (2018).

35. Clausen, B. E., Burkhardt, C., Reith, W., Renkawitz, R. \& Förster, I. Conditional gene targeting in macrophages and granulocytes using LysMcre mice. Transgenic Res. 8, 265-277 (1999).

36. Ikushima, H. \& Miyazono, K. TGFbeta signalling: a complex web in cancer progression. Nat. Rev. Cancer 10, 415-424 (2010).

37. Bassaganya-Riera, J. et al. Activation of PPAR $\gamma$ and $\delta$ by conjugated linoleic acid mediates protection from experimental inflammatory bowel disease. Gastroenterology 127, 777-791 (2004).

38. Bouguen, G. et al. Intestinal steroidogenesis controls PPARy expression in the colon and is impaired during ulcerative colitis. Gut 64, 901-910 (2015).

39. Pseftogas, A., Gonidas, C. \& Mosialos, G. Activation of peroxisome proliferatoractivated receptor gamma in mammary epithelial cells upregulates the 
expression of tumor suppressor Cyld to mediate growth inhibition and antiinflammatory effects. Int. J. Biochem. Cell. Biol. 82, 49-56 (2017).

40. Bresson, J. et al. Scientific opinion on the safety of 'conjugated linoleic acis (CLA)rich oil' (Clarinol ${ }^{\circledR}$ ) as a novel food ingredient1. EFSA Journal 8, 1601 (2010).

41. Shiraishi, R. et al. Conjugated linoleic acid suppresses colon carcinogenesis in azoxymethane-pretreated rats with long-term feeding of diet containing beef tallow. J. Gastroenterol. 45, 625-635 (2010).

42. Bruen, R., Fitzsimons, S. \& Belton, O. Atheroprotective effects of conjugated linoleic acid. Br. J. Clin. Pharmacol. 83, 46-53 (2017).

43. Song, K. et al. Anti-diabetic effect of fermented milk containing conjugated linoleic acid on type II diabetes mellitus. Korean J. Food Sci. Anim. Resour. 36, 170-177 (2016).

44. Han, L., Shen, W.-J., Bittner, S., Kraemer, F. B. \& Azhar, S. PPARs: regulators of metabolism and as therapeutic targets in cardiovascular disease. Part II: PPAR- $\beta / \delta$ and PPAR- $\gamma$. Future Cardiol. 13, 279-296 (2017).

45. Monsalve, F. A., Pyarasani, R. D., Delgado-Lopez, F. \& Moore-Carrasco, R. Peroxisome proliferator-activated receptor targets for the treatment of metabolic diseases. Mediat. Inflamm. 2013, 1-18 (2013).

46. Gou, Q., Gong, X., Jin, J., Shi, J. \& Hou, Y. Peroxisome proliferator-activated receptors (PPARs) are potential drug targets for cancer therapy. Oncotarget $\mathbf{8}$, 60704-60709 (2017).

47. Faria, A. M. C. et al. Food components and the immune system: from tonic agents to allergens. Front. Immunol. 4, 102 (2013).

48. Laukoetter, M. G. et al. Intestinal cancer risk in Crohn's disease: a meta-analysis. J. Gastrointest. Surg. 15, 576-583 (2011).

49. Lutgens, M. W. M. D. et al. Declining risk of colorectal cancer in inflammatory bowel disease. Inflamm. Bowel Dis. 19, 789-799 (2013).

50. Perše, M. \& Cerar, A. Morphological and molecular alterations in 1,2 dimethylhydrazine and azoxymethane induced colon carcinogenesis in rats. J. Biomed. Biotechnol. 2011, 473964 (2011).

51. Kadirareddy, R. H., Vemuri, S. G. \& Palempalli, U. M. D. Probiotic conjugated linoleic acid mediated apoptosis in breast cancer cells by downregulation of NFkB. Asian Pac. J. Cancer Prev. 17, 3395-3403 (2016).

52. Wang, W. et al. Dynamic changes of peritoneal macrophages and subpopulations during ulcerative colitis to metastasis of colorectal carcinoma in a mouse model. Inflamm. Res. 62, 669-680 (2013).
53. Wirtz, S. et al. Chemically induced mouse models of acute and chronic intestinal inflammation. Nat. Protoc. 12, 1295-1309 (2017).

54. Evans, N. P. et al. Conjugated linoleic acid ameliorates inflammation-induced colorectal cancer in mice through activation of PPARgamma. J. Nutr. 140, 515-521 (2010).

55. Shin, K. H., Park, Y. J. \& Park, J. G. Mutational analysis of the transforming growth factor beta receptor type II gene in hereditary nonpolyposis colorectal cancer and early-onset colorectal cancer patients. Clin. Cancer Res. 6, 536-540 (2000).

56. Medicherla, S. et al. Antitumor activity of TGF-beta inhibitor is dependent on the microenvironment. Anticancer Res. 27, 4149-4157 (2007).

57. Gabriely, G. et al. Targeting latency-associated peptide promotes antitumor immunity. Sci. Immunol. 2, eaaj1738 (2017).

58. Reeves, P. G., Nielsen, F. H. \& Fahey, G. C. AIN-93 purified diets for laboratory rodents: final report of the American Institute of Nutrition $\mathrm{Ad} \mathrm{Hoc} \mathrm{Writing}$ Committee on the Reformulation of the AIN-76A Rodent Diet. J. Nutr. 123, 1939-1951 (1993).

59. Mchenga, S. S. S., Wang, D., Li, C., Shan, F. \& Lu, C. Inhibitory effect of recombinant IL-25 on the development of dextran sulfate sodium-induced experimental colitis in mice. Cell. Mol. Immunol. 5, 425-431 (2008).

60. Santos Rocha, C. et al. Local and systemic immune mechanisms underlying the anti-colitis effects of the dairy bacterium Lactobacillus delbrueckii. PLOS ONE $\mathbf{9}$, e85923 (2014)

61. McCafferty, D. M. et al. Spontaneously developing chronic colitis in IL-10/iNOS double-deficient mice. Am. J. Physiol. Gastrointest. Liver Physiol. 279, G90-G99 (2000).

62. Rodrigues, M. A. et al. Inner nuclear membrane localization of epidermal growth factor receptor (EGFR) in spontaneous canine model of invasive micropapillary carcinoma of the mammary gland. Pathol. Res. Pract. 212, 340-344 (2016).

63. David, B. A. et al. Isolation and high-dimensional phenotyping of gastrointestinal immune cells. Immunology 151, 56-70 (2017).

64. Magness, S. T. et al. A multicenter study to standardize reporting and analyses of fluorescence-activated cell-sorted murine intestinal epithelial cells. AJP Gastrointest. Liver Physiol. 305, G542-G551 (2013).

65. Oliveira, L. S. et al. A defective TLR4 signaling for IFN- $\beta$ expression is responsible for the innately lower ability of BALB/c macrophages to produce NO in response to LPS as compared to C57BL/6. PLoS ONE 9, e98913 (2014). 